UCRL-ID-129826

\title{
Final Report: \\ Fiscal Year 1997 Demonstration of Omnivorous Non-Thermal Mixed Waste Treatment: Direct Chemical Oxidation of Organic Solids and Liquids using Peroxydisulfate
}

J.F. Cooper

G.B. Balazs

January 1998

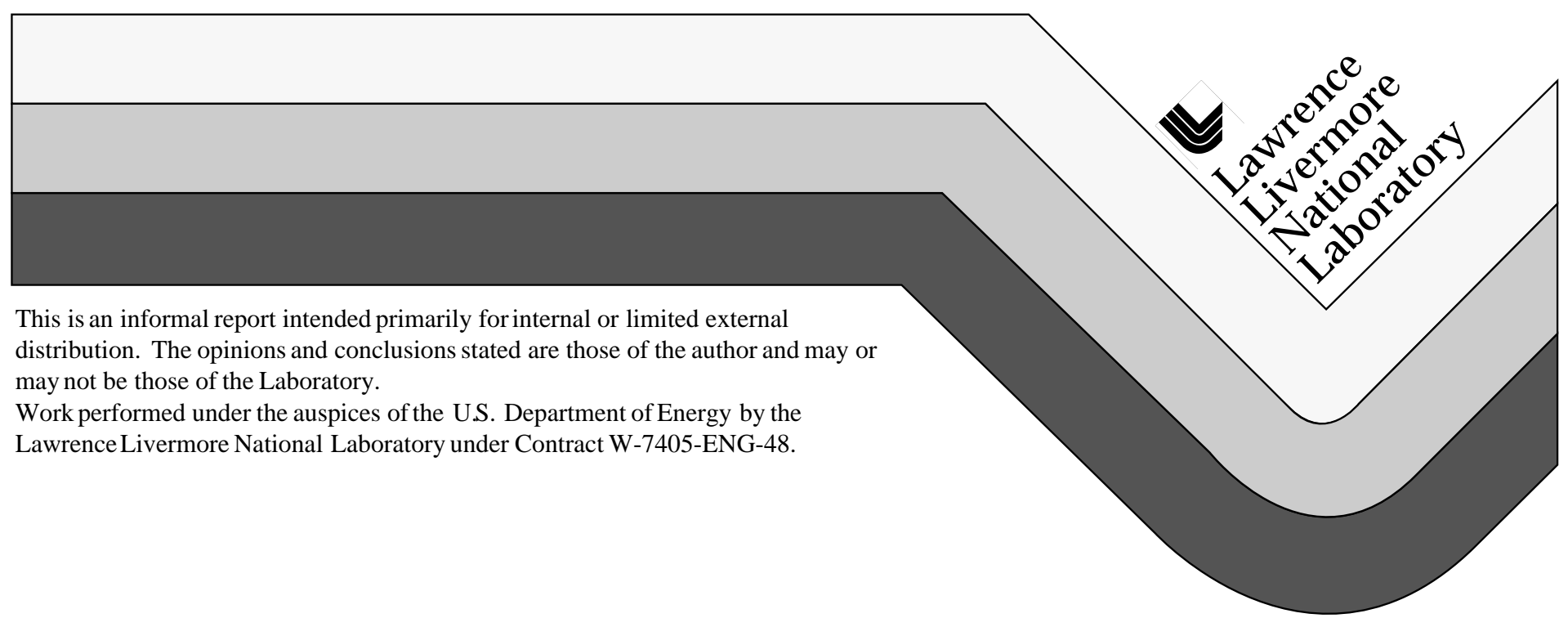




\section{DISCLAIMER}

This document was prepared as an account of work sponsored by an agency of the United States Government. Neither the United States Government nor the University of California nor any of their employees, makes any warranty, express or implied, or assumes any legal liability or responsibility for the accuracy, completeness, or usefulness of any information, apparatus, product, or process disclosed, or represents that its use would not infringe privately owned rights. Reference herein to any specific commercial product, process, or service by trade name, trademark, manufacturer, or otherwise, does not necessarily constitute or imply its endorsement, recommendation, or favoring by the United States Government or the University of California. The views and opinions of authors expressed herein do not necessarily state or reflect those of the United States Government or the University of California, and shall not be used for advertising or product endorsement purposes.

This report has been reproduced directly from the best available copy.

Available to DOE and DOE contractors from the Office of Scientific and Technical Information P.O. Box 62, Oak Ridge, TN 37831

Prices available from (423) 576-8401

Available to the public from the National Technical Information Service

U.S. Department of Commerce 5285 Port Royal Rd. Springfield, VA 22161 
DCO Final Report FY97

1

FINAL REPORT: FISCAL YEAR 1997

\section{DEMONSTRATION OF OMNIVOROUS NON-THERMAL MIXED WASTE TREATMENT:}

Direct Chemical Oxidation of Organic Solids and Liquids using Peroxydisulfate

John F. Cooper, Principal Investigator

G. Bryan Balazs, co-Investigator

September 30, 1997

\section{OVERVIEW OF TECHNOLOGY}

\section{A. Technology Description}

\section{Organics Oxidation}

Direct Chemical Oxidation (DCO) is a non-thermal, ambient pressure, aqueous-based technology for the oxidative destruction of the organic components of hazardous or mixed waste streams. The process has been developed for applications in waste treatment, chemical demilitarization and decontamination at LLNL since 1992. [1-13] The process uses solutions of the peroxydisulfate ion (typically sodium or ammonium salts) to completely mineralize the organics to carbon dioxide and water. The expended oxidant may be electrolytically regenerated to minimize secondary waste. The net waste treatment reaction is (Eq. 1):

$$
\mathrm{S}_{2} \mathrm{O}_{8}{ }^{2-}+\{\text { organics }\} \Rightarrow 2 \mathrm{HSO}_{4}^{-}+\left\{\mathrm{CO}_{2}, \mathrm{H}_{2} \mathrm{O} \text {, inorganic residues }\right\}
$$

Peroxydisulfate is one of the strongest oxidants known (oxidation potential is $+2.05 \mathrm{~V}$ ), and is exceeded only in oxidative power by fluorine, ozone, and oxyfluorides. The oxidation potential of peroxydisulfate is high enough to oxidize nearly any organic substance. [14-17]

\section{Free radical and secondary oxidant formation}

While many oxidants exhibit a redox potential capable of broad-spectrum organic oxidation, peroxydisulfate uniquely combines a high oxidation potential with a rapid, nucleophilic charge-transfer capability. Oxidation occurs principally through the formation of the sulfate radical anion $\mathrm{SO}_{4}{ }^{\bullet}$, following mild thermal $\left(80-100{ }^{\circ} \mathrm{C}\right)$, UV or catalytic activation of peroxydisulfate solutions [18-20]:

$$
\mathrm{S}_{2} \mathrm{O}_{8}{ }^{2-} \Rightarrow 2 \mathrm{SO}_{4}{ }^{-\bullet}
$$

Alternatively, this radical-generation process may be effected at near ambient temperatures (30-50 ${ }^{\circ} \mathrm{C}$ ) through the use of a catalyst such as metallic platinum, or with dissolved silver or copper ion catalysts [17]. The reaction of the sulfate free radial with the organic and with water results in a cascade of active oxidants including organic free radical fragments and hydroxyl free radicals. The decomposition of peroxydisulfate produces a number of intermediate oxidizers including peroxymonosulfate (a strong industrial bleach), hydrogen peroxide, and nascent oxygen. 


\section{Electrochemical Regeneration}

The ammonium (or sodium) hydrogen sulfate produced as a byproduct of peroxydisulfate oxidation can be recycled in a flowing electrolyte cell. Typically, industrial cells use a platinum or glassy carbon anode, an inert graphite cathode, and a porous ceramic separator to prevent cathodic reduction of the product. The anodic reaction is (Eq. 3):

$$
2 \mathrm{NH}_{4} \mathrm{HSO}_{4} \Rightarrow\left(\mathrm{NH}_{4}\right)_{2} \mathrm{~S}_{2} \mathrm{O}_{8}+2 \mathrm{H}^{+}+2 \mathrm{e}^{-} \quad \text { (anode) }
$$

while the cathodic reaction is the reduction of water to form hydrogen gas. [19] In specialized applications where the production of hydrogen gas is not desirable (such as in a confined plant), the cathodic reaction can be replaced with oxygen reduction using a porous gas diffusion electrode. This modification also reduces the cell voltage by $1 \mathrm{~V}$ (about 20\%).

The oxidant ammonium or sodium peroxydisulfate is sufficiently stable at or slightly below room temperature to be stored as a solid or a wet slurry for months. It becomes reactive only at elevated temperatures or through contact with the catalysts described above. This allows the oxidant to be slowly produced and stockpiled for use in intermittent waste treatment campaigns of short duration.

\section{Offgas stream}

The exact composition of the offgas stream will depend on the particular waste stream being processed, but several general predictions can be made. Common to all organic waste streams will be carbon dioxide; oxygen will also be produced from the direct oxidation of water by peroxydisulfate (occurring at a slower rate than oxidation of organics). Chlorine will be present in the offgas if chloro-organics are treated in an acidic DCO system. Alternatively, the use of DCO in a basic solution avoids the formation of chlorine, as the chlorine released from the destruction of the organic remains as chloride ion in solution. [18] If the oxidant is recycled by electrolysis, then oxygen, ozone, and possibly chlorine (if chloride ion is present) will be added to the offgas stream at the anode. For cells producing hydrogen, this gas is best immediately oxidized to water (in a catalyzed bed), and the water internally recycled. Commercial catalysts are available and used for this purpose.

\section{Throughput}

Based on our measured as well as literature-tabulated rate constants, the destruction of organic material is nearly independent of the particular compound. [10,14,18] Within a factor of two, the oxidation proceeds at a rate of $\sim 200 \mathrm{~kg}$ carbon content $/ \mathrm{m}^{3} / \mathrm{day}$, where $\mathrm{m}^{3}$ is the volume of the chemical oxidation reactor. [10] This throughput figure takes into consideration the fall-off in oxidant concentration as the organic material is oxidized in the reactor.

\section{B. Technical basis}

The DCO technology brings together and integrates three pre-existing technologies: (1) Total carbon analysis. This is a common laboratory analytical technique using aqueous peroxydisulfate solutions at $100{ }^{\circ} \mathrm{C}$ to oxidize any organic or inorganic carbon-containing samples to carbon dioxide for subsequent spectrographic determination. [20,21,24] (2) Recycle. DCO uses electrolysis to recycle the expended oxidant to peroxydisulfate, by the same technique used as an intermediate step in the industrial production of hydrogen peroxide (1917 to 1960, prior to the introduction of a non-electrolytic process). [19] (3) Large-scale industrial production and use of 
peroxydisulfate. Thousands of tons of ammonium peroxydisulfate are used annually to destroy hydraulic fluids used to fracture rock in enhanced petroleum recovery; massive amounts are used as industrial bleaches, etchants, reaction initiators, etc. [13] Peroxydisulfate has also been used to oxidize recalcitrant structures found in coal, as part of a coal-depolarized electrolytic production of hydrogen gas. Because of this industrial basis, large scale sulfate-to-peroxydisulfate electrolysis equipment is available for lease or purchase from various electrochemical and industrial firms. In addition, a large amount of knowledge and experience is available with regard to the potential safety issues regarding the use of peroxydisulfate, and of its recycling (see Appendix A). 


\section{Potential Waste Streams}

The general problem solved by Direct Chemical Oxidation (DCO) technology is the total oxidative destruction (by non-thermal, ambient pressure, low temperature means) of nearly any organic solid or liquid. This includes solvents, detergents, pesticides, water-insoluble oils and greases, charcoal filter media, incinerator chars and tars, paper, plastics (excepting perfluorinated polymers), chlorinated, sulfated and nitrated wastes, and organics immobilized in organic/inorganic matrices such as soils, sands or sludges.

Solutions of the oxidant can be used to treat inaccessible wastes (such as radioactivelycontaminated organics within metal machinery, glove boxes, or weapons components), as a surface etching agent for contaminated metal or plastic equipment, and in decontamination or destruction of chemical warfare agents, explosives and propellants. Potentially important applications include destruction of any organic materials in a medium containing free chloride, nitrate, phosphate, sulfate, or carbonate ions, with a reduction in secondary waste: chloride is converted to free chlorine gas, which is segregated from the waste and converted to $\mathrm{NaCl}$; carbonate is liberated as carbon dioxide; amino nitrogen is converted to ammonium ion; and nitrite ion is converted to nitrate. Since ammonium peroxydisulfate can be stored almost indefinitely at room temperature or slightly below, the process of waste destruction can be decoupled in time and place from the generation of the peroxydisulfate oxidant.

\section{Site-specific applications}

A unique application of peroxydisulfate (for which we know of no practical alternative low-temperature treatment) is the destruction of carbon residues in incinerator ash at Rocky Flats and elsewhere. Ammonium peroxydisulfate can attack and destroy recalcitrant materials such as graphite, coal dust, metal carbide, charcoal and carbon residuals found in such incinerator ashes. For example, even the glassy carbon used in some peroxydisulfate production cells is gradually consumed. Because peroxydisulfate requires no catalyst, its use is compatible with the inorganic content of common ashes.

The Quickwin '97 project for DCO (FY97) targeted mixed waste chlorinated solvents at LLNL (see Section VI). We see other site-specific applications in cellulose, Trimsol (a cutting oil), polyethylene, and latex mixed waste now stored at Rocky Flats Plant and at Los Alamos National Laboratory. These sites support work in MEO, compared with which DCO is a more omnivorous and lower cost technique. Savannah River Plant may have need for a general-purpose waste treatment technique which also is effective for the destruction of tributyl phosphate and ion exchange resins.

\section{Advantages of DCO} significance:

The advantages of Direct Chemical Oxidation are as follows, in rough order of

1.) The process is virtually "omnivorous," derived from three aspects:

(a) Peroxydisulfate is among the strongest oxidants known $(\mathrm{E}=+2.05 \mathrm{~V})$, exceeding $\mathrm{Ag}(\mathrm{II})(+1.987 \mathrm{~V}), \mathrm{Co}(\mathrm{III})(+1.84 \mathrm{~V}), \mathrm{H}_{2} \mathrm{O}_{2}(+1.8 \mathrm{~V}), \mathrm{MnO}_{4}^{-}(+1.7 \mathrm{~V})$, oxygen $(+1.2 \mathrm{~V})$; and $\mathrm{Fe}(\mathrm{III})(+0.8 \mathrm{~V})$. Peroxydisulfate is exceeded in strength only by ozone, fluorine and oxyfluorates--none of which are suitable for condensed waste treatment. [14]

(b) With thermal or UV activation, peroxydisulfate spontaneously forms the sulfate free radical $\left(\mathrm{SO}_{4}^{\bullet} \bullet\right)$ which then generates a cascade of active oxidants including hydroxyl free radical 
$\mathrm{OH} \bullet$ and organic free radicals. Secondary oxidants formed by natural decomposition of peroxydisulfate (peroxymonosulfate, hydrogen peroxide, and oxygen) may also be consumed in the net oxidation process. [18]

(c) Finally, the $\mathrm{SO}_{4}{ }^{\bullet}$ can add to certain insoluble organic compounds (chars, oils, etc.) and promote their solution or emulsification in sulfated form. Unsaturated organic molecules, which are normally insoluble in water, are readily attacked at double and triple $\mathrm{C}-\mathrm{C}$ bonds to form water soluble organic acids. Peroxydisulfate is far more reactive than hydrogen peroxide and readily oxidizes materials only slowly oxidized by WETOX (e.g., chlorinated hydrocarbons, oils and greases, plastics). [25,26]

2.) DCO is non-thermal, ambient pressure, and aqueous based:

The non-thermal characteristic would seem to eliminate the possibility of dioxin or furan formation, and one of the tasks for FY97 work was to verify this fact. The existence of double bonds in dioxins and furans make them particularly vulnerable to peroxydisulfate oxidation in an aqueous environment.

In addition, volatilization of metals or of radiouclides present in the original waste stream is drastically reduced, if not altogether eliminated. Like all aqueous phase destruction techniques, the treatment occurs in a wetted medium without generation of dust. DCO results in products suitable for further recovery or disposal of inorganic residuals by conventional techniques (precipitation, ion exchange or electrolytic recovery, encapsulation for burial).

Finally, the high heat of evaporation and heat capacity of water buffers the system against thermal runaways.

3.) DCO is effective on a diverse group of waste matrices:

These matrices include liquid organics (either miscible with water or not), organic solids, and contaminated soils, sands or sludges. As DCO is a chemical treatment, effectiveness is maximized by increasing the surface area of the material in contact with the oxidant solution. This may be accomplished by using mechanical emulsification (very rapid stirring), surfactants or sonication on immiscibles, shredding or pulverizing solids, or through chemical solubilization through formation of soluble acid intermediates.

In addition, Direct Chemical Oxidation of organics can be done in either acidic, neutral, or basic solutions. In basic solutions, organic carbon is oxidized and retained as carbonate ion. This allows the process to be operated as a nearly gas-free oxidation process suitable for glove boxes or other confined work areas.

An important class of oxidations involves surface etching of metals and plastics. This provides for organic decontamination of equipment or buildings with a minimum of secondary waste generation.

4.) Minimal secondary waste:

Because the expended oxidant (existing as sulfate or bisulfate depending on solution $\mathrm{pH}$ ) can be electrolytically recycled to peroxydisulfate, the process produces minimal secondary waste. The only offgases (other than those associated with the destruction of the organics) are oxygen and hydrogen, the latter produced at the cathode of the electrorecycle step. DCO does not entrain the large amounts of tramp water found with systems using $30 \%$ hydrogen peroxide.

5.) No catalyst required: 
The process does not require the use of toxic, expensive or degradable catalysts (such as $\mathrm{Ag}$ (II) or Co(III) used by Mediated Electrochemical Oxidation [27-29], or the dispersed Pt(IV) or $\mathrm{Ru}(\mathrm{III})$ catalysts used by DETOX [30]). DCO therefore obviates the loss of catalysts by precipitation (as, e.g., $\mathrm{AgCl}, \mathrm{Ag}_{2} \mathrm{SO}_{4}, \mathrm{CoF}_{2}, \mathrm{Ag}_{2} \mathrm{~S}$, etc.) or by entrainment in secondary waste streams. The investment in electrolysis equipment is lower than that for MEO for two reasons: (1) peroxydisulfate is produced at nearly 10 times the rate as $\mathrm{Ag}(\mathrm{II})$, per unit area of the platinum anode, and (2) a smaller recycle plant can be operated continuously and the oxidant stored without hazard or loss for eventual waste treatment campaigns.

6.) Waste destruction campaign decoupled from oxidant generation:

Solutions of peroxydisulfate are stable almost indefinitely at room temperature, and are activated either through the use of a catalyst or by heating the solution. Thus, peroxydisulfate can be produced and stored until waste treatment is begun. The electrolysis plant can be scaled down to accumulate in a continuous operation over time the oxidant used in intermittent treatment campaigns.

7.) Existing industrial basis:

Thousands of tons of ammonium peroxydisulfate are used annually as a breaker for organic hydraulic fluids used to fracture rock or penetrate sand beds in enhanced petroleum or gas recovery; similar amounts are used as industrial bleaches, etchants, reaction initiators, etc. $[9,10]$ Peroxydisulfate has also been used to oxidize recalcitrant structures found in coal, as part of a coaldepolarized electrolytic production of hydrogen gas.

The electrolytic recycling step is well-grounded in the industrial production of hydrogen peroxide used in the past. [15,19] From World War I to about 1960, hydrogen peroxide was produced by oxidation of water by peroxydisulfate, which in turn was electrochemically recycled. Because of these industrial uses, large scale sulfate-to-peroxydisulfate electrolysis equipment is available for lease or purchase throughout the world. Because of this industrial basis, both the use and recycling of peroxydisulfate are well-documented in terms of the safety issues (see Appendix A).

8.) No unresolved materials issues:

Common materials of construction for the process are perfluorinated polymers such as Teflon or Kynar, coated stainless steel, glass or ceramics, or materials such as epoxies, tars or some plastics such as polypropylene and high density polyethylene (these are only slowly degraded). For a general discussion, see references, [17,19].

9.) No problems with organic heteroatoms:

Peroxydisulfate promotes the destruction of nitrated and nitrate-containing wastes. Ammonium nitrate products are decomposed thermally into nitrogen and/or $\mathrm{N}_{2} \mathrm{O}$ in the presence of chloride catalysts. The waste treatment system can be configured to treat chlorinated wastes, consuming transient chlorine or oxychloride species by oxidation of organic intermediates, resulting in a final product containing chlorides and sulfates.

\section{0.) Versatile scaling:}

An important aspect of this technology is its ability to scale down without loss of efficiency. Bench-top units are useful in future DOE or DOD production facilities to destroy undifferentiated wastes produced as a byproduct of routine chemical analyses. DCO can be used as a dedicated unit process to destroy wastes produced in small industry production lines. At the 


\section{DCO Final Report FY97 \\ 7}

$200 \mathrm{~kg}$ carbon/day level, the process is fully transportable with a reactor volume of $\sim 1 \mathrm{~m}^{3}$. The ability to store stable solutions or precipitates of peroxydisulfate salts adapts well to intermittent waste treatment campaigns. 


\section{PRIOR WORK}

\section{A. Prior work FY92-FY95}

We have been conducting research on a Direct Chemical Oxidation process at LLNL since 1992 for application to the organic fraction of mixed wastes, to the destruction of chemical warfare agents, and for general applications to demilitarization [1-14]. (Total internal funding by Livermore Directed Research and Development to date, $\sim \$ 150 \mathrm{~K})$.

In 1994, DOWEX ion exchange resins were rapidly destroyed in uncatalyzed peroxydisulfate solution at $100{ }^{\circ} \mathrm{C}$. We constructed an electrolysis cell replicating the industrial process (Loewenstein process) and used it to produce peroxydisulfate for subsequent destruction tests on model chemicals at high concentrations in water. We adapted a total carbon analyzer and used it to determine the overall rates of destruction of 20 chemicals bearing functional groups commonly found in DOE wastes. A summary of the kinetic data is given in Table I. Included also were surrogates for chemical warfare agents: VX, HD and GB. Within a factor of 2, the rates of destruction of these diverse chemicals are constant, indicating that the controlling rate factor is the formation of the sulfate radical anion. We derived and verified a quantitative model for destruction of concentrated solutions of ethylene glycol (a reference chemical used to test aqueous waste destruction techniques), and measured the parasitic oxidation of water. This work indicated that organic wastes can be destroyed in a one cubic meter plug flow reactor at a rate of $200 \mathrm{~kg}$ carbon per day. The results from this internally-funded work are summarized in a paper recently published in the International Conference for Waste Treatment and Environmental Remediation [10].

Table I. Integral first order rate constants $\mathrm{k}_{\mathrm{a}}$ calculated from the extent of oxidation $\mathrm{E}$, as measured by $\mathrm{CO}_{2}$ evolution using a total carbon analyzer ${ }^{\mathrm{a}}$. Given are molecular and equivalent weights, initial concentration and oxidant/reductant ratio, and initial and final $\mathrm{C}$ concentrations for fixed oxidation rates. The extent of oxidation was used to calculate a rate constant for the first order equation in equivalents, $\mathrm{d}[\mathrm{R}] / \mathrm{dt}=-\mathrm{k}_{\mathrm{a}}\left[\mathrm{S}_{2} \mathrm{O}_{8}{ }^{2-}\right.$.

\begin{tabular}{|c|c|c|c|c|c|c|c|c|c|c|}
\hline No & Compound & $\mathrm{M}_{\mathrm{W}}$ & $\mathrm{n}$ & $(\mathrm{R}(0))$ & $\mathrm{Ratio}$ & $\mathrm{C}(0)$ & $\mathrm{C}(\mathrm{t})$ & $\mathrm{Dt}$ & $\mathrm{E}$ & $10^{2} \mathrm{k}_{\mathrm{a}}$ \\
\hline & & $\mathrm{g} / \mathrm{mol}$ & $\mathrm{eq} / \mathrm{mol}$ & $\mathrm{mM}$ & $[\mathrm{O}] / \mathrm{R}]$ & $\mathrm{ppm}$ & $\mathrm{ppm}$ & $\mathrm{min}$ & $\%$ & $1 / \mathrm{min}$ \\
\hline 1 & Urea & 60.06 & 0 & 1.16 & $\mathrm{~N} / \mathrm{A}$ & 43.19 & 41.03 & 2.5 & 95 & 0.36 \\
\hline 2 & oxalic acid dihydrate & 126.00 & 2 & 1.17 & 116.86 & 43.47 & 44.00 & 2.5 & 101 & 0.38 \\
\hline 3 & nitromethane & 61.04 & 8 & 2.51 & 13.59 & 46.76 & 41.61 & 11.5 & 89 & 0.63 \\
\hline 4 & Salicylate-Na salt & 160.10 & 28 & 0.36 & 27.14 & 46.81 & 46.17 & 5.5 & 99 & 0.73 \\
\hline 5 & formic acid & 46.03 & 2 & 2.47 & 55.14 & 46.09 & 42.25 & 2.5 & 92 & 0.73 \\
\hline 6 & Triethylamine & 101.19 & 36 & 0.14 & 53.62 & 15.80 & 14.70 & 2.5 & 93 & 0.76 \\
\hline 7 & DMSO & 78.13 & 18 & 1.30 & 11.67 & 48.40 & 46.46 & 11.5 & 96 & 0.79 \\
\hline 8 & DIMP & 180.18 & 44 & 0.18 & 34.57 & 23.39 & 23.20 & 2.5 & 99 & 1.26 \\
\hline 9 & Na-EDTA & 372.24 & 39 & 0.22 & 31.25 & 41.71 & 39.67 & 2.5 & 95 & 1.34 \\
\hline 10 & 4 -chloropyridine HCL & 150.01 & 21 & 0.46 & 28.04 & 43.15 & 39.26 & 2.5 & 91 & 1.43 \\
\hline 11 & 4-amino-pyridine & 94.12 & 20 & 0.47 & 28.82 & 44.09 & 42.33 & 2.5 & 96 & 1.47 \\
\hline 12 & acetic acid & 60.05 & 8 & 1.19 & 28.64 & 44.36 & 44.54 & 2.5 & 100 & 1.54 \\
\hline 13 & sucrose & 342.29 & 48 & 0.20 & 28.01 & 45.35 & 44.79 & 2.5 & 99 & 1.55 \\
\hline 14 & Methylphosphonic acid & 96.02 & 8 & 1.21 & 28.20 & 22.53 & 22.50 & 2.5 & 100 & 1.56 \\
\hline 15 & $2,2 '$-thiodiethanol & 122.18 & 28 & 0.38 & 25.47 & 28.51 & 28.30 & 2.5 & 99 & 1.71 \\
\hline 16 & 1,4-dioxane & 88.11 & 20 & 0.63 & 21.73 & 46.79 & 44.84 & 2.5 & 96 & 1.94 \\
\hline 17 & ethylene glycol & 62.07 & 10 & 1.28 & 21.27 & 47.80 & 44.96 & 2.5 & 94 & 1.95 \\
\hline 18 & formamide & 45.04 & 5 & 2.52 & 21.68 & 46.90 & 46.47 & 2.5 & 99 & 2.01 \\
\hline 19 & Na-lauryl sulfate & 288.38 & 72 & 0.21 & 17.99 & 47.08 & 44.71 & 2.5 & 95 & 2.32 \\
\hline
\end{tabular}


DCO Final Report FY97

9

${ }^{\mathrm{a}}$ Conditions: $\mathrm{T}=100^{\circ} \mathrm{C} ;\left[\mathrm{H}_{3} \mathrm{PO}_{4}\right]=0.0574 \mathrm{M} ;\left[\mathrm{S}_{2} \mathrm{O}_{8}{ }^{2-}\right]=0.245 \mathrm{~N} ; 0.3 \mathrm{~cm}^{2} \mathrm{Pt}$ wire catalyst. 
Researchers at Hanford have used solutions of peroxydisulfate (with and without a $\operatorname{Ag}(\mathrm{I})$ mediator) to clean metal equipment by combined etching and organic oxidation. The solution allows recovery of $\mathrm{PuO}_{2}$ as water-soluble $\mathrm{Pu}(\mathrm{VI})$ (plutonyl) species. Plutonyl ion is soluble up to $\sim 100 \mathrm{~g} / \mathrm{L}$ in acidified solutions containing peroxydisulfate/sulfate with and without silver(II). [11] Peroxydisulfate improves on the organic oxidizing ability of $\mathrm{Ag}(\mathrm{II})$ by operating as a strong nucleophilic charge transfer agent and by producing $\mathrm{Ag}$ (II) oxidizing species within the bulk of the electrolyte (as opposed to adjacent to the electrode in MEO). Similarly, peroxydisulfate with or without a silver mediator (Table II) has been used to oxidize and render soluble various actinide compounds containing $\mathrm{U}, \mathrm{Pu}, \mathrm{Np}, \mathrm{Am}, \mathrm{Cm}$ or $\mathrm{Bk}$, as studied by various Soviet and French researchers.

Table II. Oxidative-dissolution of actinides by ammonium peroxydisulfate (APS). In most cases, APS is driver for $\mathrm{Ag}(\mathrm{II})$ charge transfer catalyst.

\begin{tabular}{|c|c|c|}
\hline Reaction & Catalyst? & Reference \\
\hline $\mathrm{Pu}(\mathrm{IV})=>\mathrm{Pu}(\mathrm{VI})$ (soluble: $90 \mathrm{~g} / \mathrm{L})$ & $\begin{array}{c}\text { none or Ag; 0.5 M } \\
\text { APS }\end{array}$ & Fisher (Hanford) (1991) \\
\hline $\mathrm{Pu}(\mathrm{IV})=>\mathrm{Pu}(\mathrm{VI})$ & $\mathrm{Ag}$ in APS & Seaborg (1955) \\
\hline $\mathrm{U}(\mathrm{IV})=>\mathrm{U}(\mathrm{V})$ & - & Manok (1973) \\
\hline $\mathrm{U}(\mathrm{V})=>\mathrm{U}(\mathrm{VI})$ & none or Fe & Manok (1973) \\
\hline $\mathrm{Am}(\mathrm{III})=>\mathrm{Am}(\mathrm{IV})$ & none or Ag & Milukova (1989) \\
\hline $\mathrm{Am}(\mathrm{III})=>\mathrm{Am}(\mathrm{IV})=>\mathrm{Am}(\mathrm{VI})$ & Ag with APS & Litvina (1988) \\
\hline $\mathrm{Am}(\mathrm{III})=>\mathrm{Am}(\mathrm{IV})=>\mathrm{Am}(\mathrm{VI})$ & $\mathrm{Ag}$ in APS, phosphate & Milyukova (1980) \\
\hline $\mathrm{Am}(\mathrm{III})=>\mathrm{Am}(\mathrm{IV})$ & Ag in APS, Nitrate & Myasoedov (1976) \\
\hline $\mathrm{Bk}(\mathrm{III})=>\mathrm{Bk}(\mathrm{IV})$ & Ag in APS, Nitrate & Milyukova (1977) \\
\hline $\mathrm{Np}, \mathrm{Cm}, \mathrm{Ce}, \mathrm{Cr}$, etc. & Ag in APS & various authors \\
\hline
\end{tabular}

\section{B. Prior Work FY96}

In FY96, we constructed and operated a plug-flow reactor (PFR) system with real-time analysis of the offgas using a mass spectrometer. This prior year testing was successfully completed to demonstrate that the proposed chemical oxidation process using peroxydisulfate was able to treat specific "difficult wastes" such as chlorinated solid and liquid wastes, proof of recycle of the oxidant, and establishing a facility consisting of batch and flow reactors with mass spectrographic offgas analysis capability for treatability studies. Specifically:

(1) The plug flow reactor (PFR) system was applied to the analysis of model chemicals such as ethylene glycol. From this work, it was concluded that PFR was capable of supporting destruction of soluble organics at a rate of 100-400 kg-Carbon/day- $\mathrm{m}^{3}$, based on reactor volume.

(2) Kerosene was destroyed in batch reactors to DRE of $99.991 \%$ after 140 minutes at 100 ${ }^{\circ} \mathrm{C}$. The reaction was substantially complete at 70 minutes, where the DRE was $99.977 \%$. Tests on bulk triethylamine showed a destruction of $>99.97 \%$ after 21 minutes at $100{ }^{\circ} \mathrm{C}$, with $95 \%$ of the amino nitrogen being converted to ammonium ion and 5\% to nitrate/nitrite. Cotton rags (cellulose, oil and dye) were substantially (>95\%) destroyed after 40 minutes, but incomplete contacting of the cotton with the reaction medium prevented measurement of a DRE. With proper contacting, cellulose is completely destroyed.

(3) Tributyl phosphate tends to polymerize under conditions of deficient oxidant, but this does not occur with equal volume mixtures of TBP and kerosene. Methyl phosphonic acid and diisopropyl-methyl-phosphonate were quantitatively oxidized at $100{ }^{\circ} \mathrm{C}$. 
(4) The liquid chlorinated compound 4-chloro-pyridine $\mathrm{HCl}$ was substantially oxidized after 12 minutes, but at a rate which was decreased by the presence of chloride ion in the solution. In a series of tests with chloride, perchlorate and ethylene glycol, we found the following: chloride slows the oxidation of the organic by competing for the available oxidant. Chloride is oxidized to chlorine, which is liberated as a gas, but no higher oxidation states (chlorate, perchlorate) were found following oxidation. Chlorine is readily scrubbed from the offgas and converted to $\mathrm{HCl}$ in an electrolysis cell: $\mathrm{Cl}_{2}+\mathrm{H}_{2} \mathrm{O} \Rightarrow 2 \mathrm{HCl}+1 / 2 \mathrm{O}_{2}$.

(5) Pure PVC polymer (without fillers or plasticizers) was found resistant to peroxydisulfate oxidation. Following thermal treatment $\left(140-180{ }^{\circ} \mathrm{C}, 24 \mathrm{~h}\right)$ under sub-pyrolysis (non charring) conditions, the PVC was partially reduced to form double bonds with liberation of trace $\mathrm{HCl}$. Following this treatment, the PVC was oxidized by peroxydisulfate. Chars from the full pyrolysis of PVC were oxidized. Analogous results were found with various plasticized PVC, including Tygon tubing.

(6) Tests conducting with a rotating disk electrode system and with a $100 \mathrm{~A}$ bench electrolysis cell showed that low levels of organic contaminants (oxalic, formic acid) did not alter either the voltage or Faradaic efficiency of peroxydisulfate production (see Figure 1).

(7) Several sources of industrial electrolysis equipment were identified for the task of product sulfate recycle to ammonium peroxydisulfate.

Figure 1. The rate of production of peroxydisulfate oxidant using industrial liquors (broken line) is compared with solutions derived from waste treatment scenarios having nitrate, phosphate or chloride contaminations at $0.1 \mathrm{M}$ levels. Current density was $1 \mathrm{~A} / \mathrm{cm}^{2}$. Broken line indicates position of $80 \%$ efficient production.

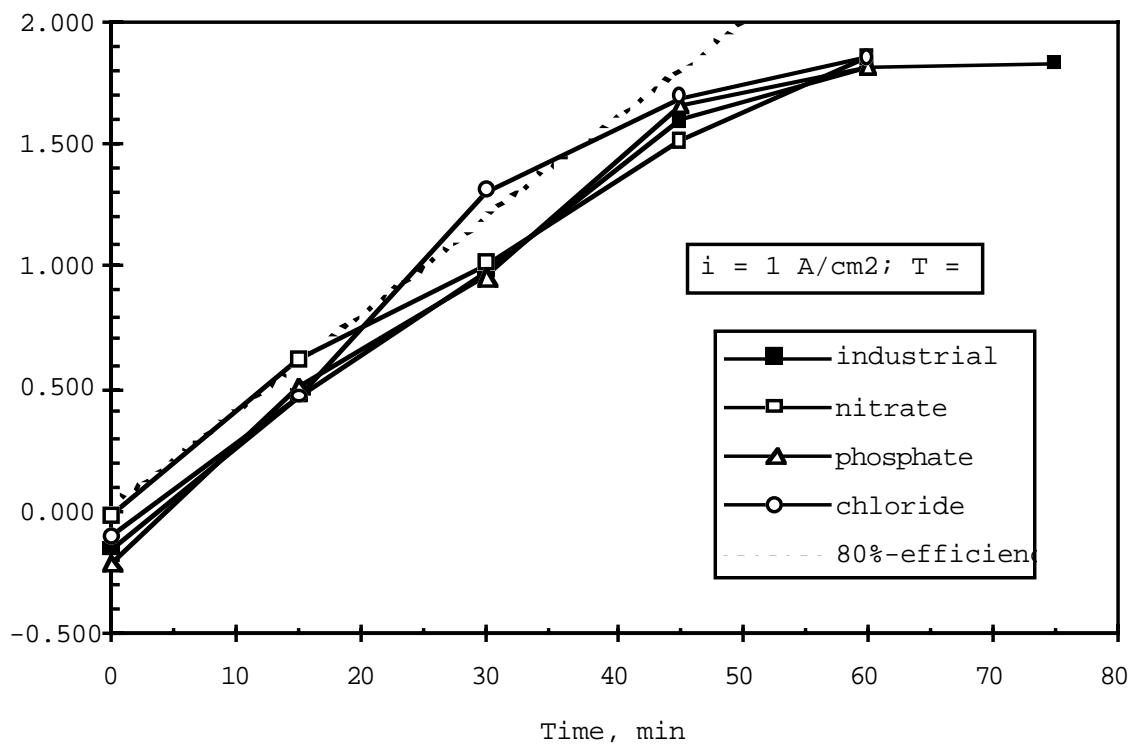


References to Parts I and II.

1. John F. Cooper, F. Wang, J. Farmer, R. Foreman, T. Shell and K. King, "Direct Chemical Oxidation of Hazardous and Mixed Wastes" (Proc. of the Third Biennial Mixed Waste Symposium, American Society of Mechanical Engineers; Aug. 1995), Lawrence Livermore National Laboratory Report UCRL-JC-120141 March 28, 1995.

2. John F. Cooper, F. Wang, J. Farmer, M. Adamson, K. King and R. Krueger, "Direct Chemical Oxidation: Peroxydisulfate destruction of organic wastes," Proc. World Environmental Congress, International Conference and Trade Fair, Page 219, London Ontario, Sept. 17-22, 1995.

3. F. Wang, J. F. Cooper, J. Farmer, M. Adamson and T. Shell, "Destruction of ion exchange resins by wet oxidation and by direct chemical oxidation--a comparison study," Proc. World Environmental Congress, International Conference and Trade Fair, p. 206; London Ontario, Sept. 17-22, 1995.

4. John F. Cooper, Francis Wang, Roger Krueger, Ken King, Joseph C. Farmer, and Martyn Adamson, "Destruction of organic wastes by ammonium peroxydisulfate with electrolytic regeneration of the oxidant," LLNL Internal Report, September 1995. UCRL-121979 Rev 1, October 10, 1995.

5. John F. Cooper, Roger Krueger and Joseph C. Farmer, "Destruction of VX by aqueousphase oxidation using peroxydisulfate: Direct chemical oxidation," (Proc. Workshop on Advances in Alternative Demilitarization Technologies, pp. 429-442, Reston VA September 2-7 1995, published by SAIC Aberdeen, MD)

6. John F. Cooper, Francis Wang, Roger Krueger, Ken King, Thomas Shell, Joseph C. Farmer, and Martyn Adamson, "Demonstration of omnivorous non-thermal mixed waste treatment: Direct chemical oxidation using peroxydisulfate," First Quarterly Report to Mixed Waste Focus Group, SF2-3-MW-35 October - December 1995; UCRL-ID-123193, February 1996.

7. John F. Cooper, "Large-area decontamination using Peroxydisulfate with UV and metal-ion catalysis," US Patent disclosure and record of invention, IL-9875, November 211995.

8. John F. Cooper (with Joseph C. Farmer, Francis T. Wang, and Martyn G. Adamson, "Alternatives to Incineration," (Proc. ASME/EPRI Radwaste Workshop, New Orleans, LA, July 24-6 1996.)

9. John F. Cooper, Francis Wang Thomas Shell, and Ken King, "Destruction of 2,4,6trinitrotoluene using ammonium peroxydisulfate," LLNL Report UCRL-ID-124585, July 1996. 
10. John F. Cooper, Francis Wang, Roger Krueger and Ken King, "Destruction of organic wastes with electrolytic regeneration of the oxidant," Proc. Sixth International Conference on Radioactive Waste Management and Environmental Remediation, Singapore October 1216 1997. UCRL-JC--121979 rev 2 July 1997.

11. Balazs, G. B. and Cooper, J. F., "The Effect of Trace Additives on the Efficiency of Peroxydisulfate Regeneration," in preparation.

12. J. Cooper, F. Wang, B. Balazs, R. Krueger, P. Lewis, T. Shell, J. Farmer, M. Adamson, "Destruction of organic wastes by ammonium peroxydisulfate," presented at AIChE Spring National Meeting (March 9-13, 1997), Houston, TX, UCRL-MI-126794.

13. Cooper, J. F., Wang, F., Balazs, G. B., Shell, T., Krueger, R., Lewis, P., Adamson, M., "Omnivorous Waste Destruction Process Using Uncatalyzed Peroxydisulfate Solutions," poster presentation at WM '97 conference, Tuscon, Arizona, March 2-6, 1997, UCRL-MI126764.

14. W. M. Lattimer, The oxidation states of the elements and their potentials in aqueous solutions, Prentice Hall, NY.

15. "Peroxides and Peroxy Compounds, Inorganic," Encyclopedia of Chemical Technology, V. 17, ed. Kirk Othmer.

16. D. A. House, "Kinetics and mechanism of oxidations by peroxydisulfate," Chem. Rev. 62, 185, (1961).

17. Francesco Minisci, Attillio Citterio and Claudio Giordano, "Electron-transfer processes: peroxydisulfate, a useful and versatile reagent in organic chemistry," Acc. Chem. Res. v. 16 27 (1983).

18. Gary R. Peyton, "The free-radical chemistry of persulfate-based total organic carbon analyzers," Marine Chemistry 41, 91-103 (1993). see also: Neta, P., Huie, R.E., and Ross, A.B., "Rate constants for reaction of inorganic radicals in aqueous solution," J. Phys. Chem. Ref. Data, 17: 1027-1284, 1988.

19. Walter C. Schumb, Charles N. Satterfield, Ralph L. Wentworth, Hydrogen Peroxide, (Reinhold Publishing, Inc., New York, 1955). Also, Wolfgang Thiele and Hermann Matschiner, "Zur elektrosynthese von Wasserstoffperoxid und Peroxodisulfaten, Teil I. Wasserstoffperoxid und Peroxodischwefelsauer," Chem. Techn. v. 29(3) p. 148 (1977).

19. I. M. Kolthoff and I. K. Miller, "The chemistry of persulfate. I. The kinetics and mechanism of the decomposition of the persulfate ion in aqueous medium," J. Am. Chem. Soc., p. 3055 July (1951). 
20. P. D. Goulden and D. H. J. Anthony, "Kinetics of uncatalyzed peroxydisulfate oxidation of organic material in fresh water," Analytical Chemistry 50(7) 953 (1978).

25. F. D. Fisher, G. S. Barney, T. D. Cooper and M. J. Duchsherer, "Silver-catalyzed $\mathrm{PuO}_{2}$ Dissolution with Persulfate," (Westinghouse Hanford Company Report WHC-SA-1170FP, June 1991).

25. T. Piccinno, A. Salluzzo, and L. Nardi, "Wet oxidation by hydrogen peroxide for the treatment of mixed radioactive and toxic organic wastes and waste waters," Waste Management, v. 11, 125 (1991).

26. J. P. Wilks, and N. S. Holt, "Wet oxidation of mixed organic and inorganic radioactive sludge wastes from a water reactor," Waste Management, v. 10 p. 197 (1990). See also, J. P. Wilks, D. J. Holman and N. S. Holt, (AEA Technology), "Pilot scale demonstration of spent ion exchange resin treatment by wet oxidation," paper submitted to the 1991 Joint International Waste Management Conference.

27. Joseph Farmer, "Electrochemical treatment of mixed and hazardous Wastes," (Chapter in "Environmental Oriented Electrochemistry," ed. Cesar A. C. Sequeira, Elsevier Science Publishers B.V., Amsterdam, The Netherlands; 1994).

28. Zoher Chiba, Bruce Schumacher, Patricia Lewis and Laura Murguia, "Mediated electrochemical oxidation as an alternative to incineration for mixed wastes" (Proc. Waste Management 95 Symposium Tucson Arizona March 1 1995).

29. Joseph C. Farmer, Francis T. Wang, Patricia R. Lewis, and Leslie Summers, Destruction of chlorinated organic by cobalt(III)-mediated electrochemical oxidation, J. Electrochem Soc. v. 139(11) 3025 (1992).

30. P. M. Dooge, "DETOX wet oxidation for treatment of complex hazardous and mixed wastes," (Proc. 1993 Incineration Conference, Knoxville, TN May 1993 p. 479.); see also Terry W. Rogers, Patrick M. Dhooge, "DetoxSM-An innovative mixed waste treatment method (Proc. 1994 Federal Environmental Restoration III and Waste Minimization II Conference and Exhibition, April 27-9 1994; New Orleans).

21. Model 700 TOC Total Organic Carbon Users Manual, (O.I. Analytical, Inc.; Graham road at Wellborn Rd. PO Box 2980; College Station TX 77841-2980).

23. Uses of Persulfate (FMC, Inc. Buffalo NY; 1951; 1960). 
III. FY97 TASKS

DCO Final Report FY97

15

\section{A. Overview}

The purpose of this year's work was to demonstrate the versatility and practicality of an "omnivorous" waste treatment process, which uses recycled ammonium or sodium peroxydisulfate to destroy surrogates for any organic solid or liquid waste of importance to DOE. The FY97 effort includes: (1) Highly specialized waste: detailed mass balance, rate, flow-charting and economic studies of two waste streams chosen by the Mixed Waste Focus Group in consultation with LLNL and a prospective user, (2) Integrated system demonstration of this process on chlorosolvents and organic-contaminated soils/sludges at a rate of 5-15 kg carbon/day, and (3) Pilot demo: a RCRA treatability study on a pilot scale in a batch or plug flow reactor at rates of $15 \mathrm{~kg}$ carbon/day using chlorinated solvents (Quickwin '97 project). Details on the specific accomplishments for each of these subtasks are in Sections IV, V, and VI below. Note that much of the process chemistry work and engineering development and scale-up for the Quickwin '97 Project is contained in Sections IV and V. Because of the intertwined nature of the work on chlorinated solvents, it was not possible to separate these into distinct and separate sections.

\section{B. Indicators of Performance for FY97 work}

The key performance indicator is the rate of organic destruction per unit volume of reaction vessel. Based on our prior work (below), we expect that broad categories of water-entrained wastes can be destroyed to sub ppm levels at a rate of $200 \mathrm{~kg}$ carbon/day per cubic meter of reaction vessel.

A second key performance indicator is completeness of destruction. Some commercial carbon analyzers using peroxydisulfate detect carbon by oxidative destruction down to levels of 100 parts-per-billion. Typical laboratory analyzers detect carbon by measuring carbon dioxide evolved by oxidization of the unknown to levels of 0.5 parts-per-million.

A third key performance indicator is the efficiency of the recycling of sulfate to peroxydisulfate. In an integrated system, we expect to recycle peroxydisulfate at $>80 \%$ efficiencies at $\mathrm{T}=20-30{ }^{\circ} \mathrm{C}$. This efficiency has been achieved by industrial plants as well as by our laboratory cells. [1,7]

A fourth key performance indicator is demonstration of general applicability, by treatment of such varied wastes as chlorinated solvents and plastics, charcoal and charcoal filters, incinerator carbon-containing chars, paper and rags, oils and greases, ion exchange resins, nitrated and nitratecontaining wastes, complexing agents (tributyl phosphate), cutting oils (Trimsol), detergents and complexing agents.

\section{Summary of Progress for FY97}

We have developed the process chemistry of the DCO technology for a number of specialized wastes (including contaminated sludges, heavily chlorinated materials, carbon tetrachloride, and polychlorinated biphenyls), completed the design, engineering, and construction of an Integrated System to demonstrate this process for several waste streams, and begun a treatability study of low-level chlorosolvent mixed waste stored at LLNL. Sections IV, V and VI detail the progress made in these areas.

In addition, we have completed a Personnel Exchange with Perma-Fix Environmental Services, Inc. with the goal of incorporating the DCO organic treatment technology into the existing Perma-Fix Process for the treatment of the inorganic components of mixed wastes. Although DCO commercialization work under EM-50 in FY98 is scheduled, it was believed to be 
in the interest of both parties to proceed as quickly as possible and thus this SBIR Personnel Exchange (funded under Defense Programs, PE\#960003) was initiated. The goal of this Personnel Exchange was to develop a conceptual design for a pilot plant demo at the Perma-Fix Gainesville facility, and this task has been accomplished.

Specifically, the technical accomplishments for DCO in FY97 were:

(1) Testing was completed on the direct oxidation of volatile chlorosolvents by peroxydisulfate, including methyl chloroform, methylene chloride, trichloroethylene, perchloroethylene, chloroform, and carbon tetrachloride. In addition, the use of catalysts to allow the oxidative process to proceed at near ambient temperatures was investigated, and work initiated.

(2) A small scale mock up of the vertical plug flow reactor to be used in the treatability study of the destruction of chlorosolvents (under Quickwin '97) was designed, built and tested. This system was latter found to be unnecessarily difficult to scale up, and a new system (cascaded CSTR) was designed and built. See accomplishments \#3 and \#4 below.

(3) The process chemistry and mechanistic and kinetic data were defined for a hydrolysis step, which is a pretreatment approach useful in the treatment of insoluble or volatile chlorosolvents. Subsequent oxidation of the prehydrolysis product results in quantitative oxidation of the organic.

(4) Engineering support was added to the project to design an integrated system, for demonstration in FY1997. This system is composed of a 70 liter hydrolysis vessel, followed by a cascading series of three, 17 liter Continuous Stirred Tank Reactors (CSTR). This system is fully operational and has been tested on a variety of chlorosolvent wastes.

(5) Batch reactor studies were completed on the oxidation of organics contained in a sludge matrix, and an experimental protocol was developed to determine the extent of destruction.

(6) Process chemistry and engineering data has been transferred to the EM-30 partner in this project (John Bowers, LLNL) for a treatability study of $300 \mathrm{~kg}$ of mixed chlorosolvents (Quickwin '97).

(7) Standards and an experimental protocol for the testing of the DCO process on PCB's has been developed, and regulatory/ES\&H issues addressed. Initial testing of the effectiveness of DCO for PCB destruction has been completed.

(8) Design and procurement of equipment for a laboratory-scale system for the treatment of organic contaminated sludges or soils is complete, and experimental work completed. Design and procurement of equipment for this same task using the Integrated DCO system (\#4 above) is complete, but testing was postponed until October 1997. (These tests are ongoing as of the time of writing).

(9) Development of a collaborative effort with Perma-Fix Environmental Services, Inc. for the transfer of this technology to the commercial sector has begun, and a Personnel Exchange (PE\#960003) has been completed. In addition, a draft of a CRADA/Statement of Work has been written. This collaboration has as its primary goal the incorporation of the DCO technology by 
DCO Final Report FY97

17

Perma-Fix into its existing inorganic mixed waste treatment technology in order to expand the potential waste streams treatable by Perma-Fix. 


\section{Management}

Project management was headed by Martyn Adamson at LLNL. This final report describes the accomplishments and technical scope achieved in FY97, and an addendum to this report will be written for the accomplishments achieved in FY98.

Milestone Title

Final Report

Addendum to Final Report

\section{Completion Date}

Date Due: 09/30/97

Date Due: $\quad 02 / 28 / 98$ 


\section{SUBTASK I.}

\section{A. Specific accomplishments for Subtask I}

\section{General Experimental Protocol}

For the work covered in Subtask I, the use of the term "laboratory scale" reactor systems refers to a 0.5 or 1.0 liter glass reaction vessel for the oxidation, and a 2.1 liter stainless steel autoclave reactor system for the hydrolysis. Both reactor systems have dedicated thermal control and measurement, and the hydrolysis vessel has an electronic pressure transducer with a pressure relief safety valve.

The oxidation reactors have a reflux condenser in the offgas line, and the offgas was pumped through a chlorine trap consisting of a potassium iodide solution. In this manner, the amount of chlorine released from the destruction of the organic could be determined subsequent to a run by standard iodometric procedures. Following the chlorine trap, the offgas was then pumped through a water trap, and then to a dedicated infra-red carbon dioxide analyzer. The offgas flow rate was also measured, and the combination of flow rate and \% carbon dioxide in the offgas was recorded in real time using a data acquisition system and LabView.

Both oxidation and hydrolysis experiments were done in the batch mode, whereby the organic substrate was added to the appropriate reactor with the required solution, and then brought up to temperature. Carbon dioxide was measured continuosly in the offgas for the oxidation reactor, and samples for either GC-MS, Total Organic Carbon, or IR analysis were taken from both reactors as necessary.

\section{Chlorosolvent destruction using peroxydisulfate}

Heavily chlorinated wastes present unusual challenges for aqueous destruction techniques such as DCO due to the fact that many of these materials, such as 1,1,1-trichloroethane, perchloroethylene, trichlorethylene, etc., are only sparingly soluble in water. Because of this, oxidation of these materials typically is limited by solution contact which occurs only at the interface of the two phases. In addition, many of these chlorinated materials are very volatile and thus are swept into the offgas before full oxidative destruction can occur.

The data from initial batch tests done this year on these chlorosolvents are shown in Table III, and the results showed virtually quantitative destruction of these materials.

Table III. Extent of oxidation of chlorinated hydrocarbons in acidic peroxydisulfate subjected to one- or three successive doses of oxidant (of 1/3 strength).

\begin{tabular}{|c|c|c|c|}
\hline $\begin{array}{c}\text { Organic } \\
\text { Substrate }\end{array}$ & $\begin{array}{c}\text { Operation } \\
\text { Mode }\end{array}$ & $\begin{array}{c}\text { Extent of oxidation } \\
\text { (for 1 dose oxidant) }\end{array}$ & $\begin{array}{c}\text { Extent of oxidation } \\
\text { (for 3 doses oxidant) }\end{array}$ \\
\hline Perchloroethylene & Batch Reactor & $68 \%$ & $99.1 \%$ \\
\hline Trichloroethylene & Batch Reactor & $75 \%$ & $99.6 \%$ \\
\hline Methylene chloride & Batch Reactor & $99 \%$ & $99.1 \%$ \\
\hline Chloroform & Batch Reactor & - & $96.7 \%$ \\
\hline $\begin{array}{c}\text { PCE/Chloroform } \\
\text { mixt. }\end{array}$ & Batch Reactor & - & $99.1 \%$ \\
\hline
\end{tabular}

Based on these results, a smaller scale mock up of the vertical packed bed reactor system to be used for the Quickwin '97 work (Subtask III, Section VI below) was designed, built and tested. This reactor is shown in Figure 2. However, after extensive testing with varied operating parameters, it was determined that the DCO process did not work as well in this continuous, bench 
scale operation as it did in the laboratory scale batch tests shown in Table III. The destruction of perchlorethylene and especially 1,1,1-trichloroethane (based on conversion to carbon dioxide) was lower than expected; these bench scale results from this mock up are shown in Table IV. 
Figure 2.

D C O VerticalChemical Reactor

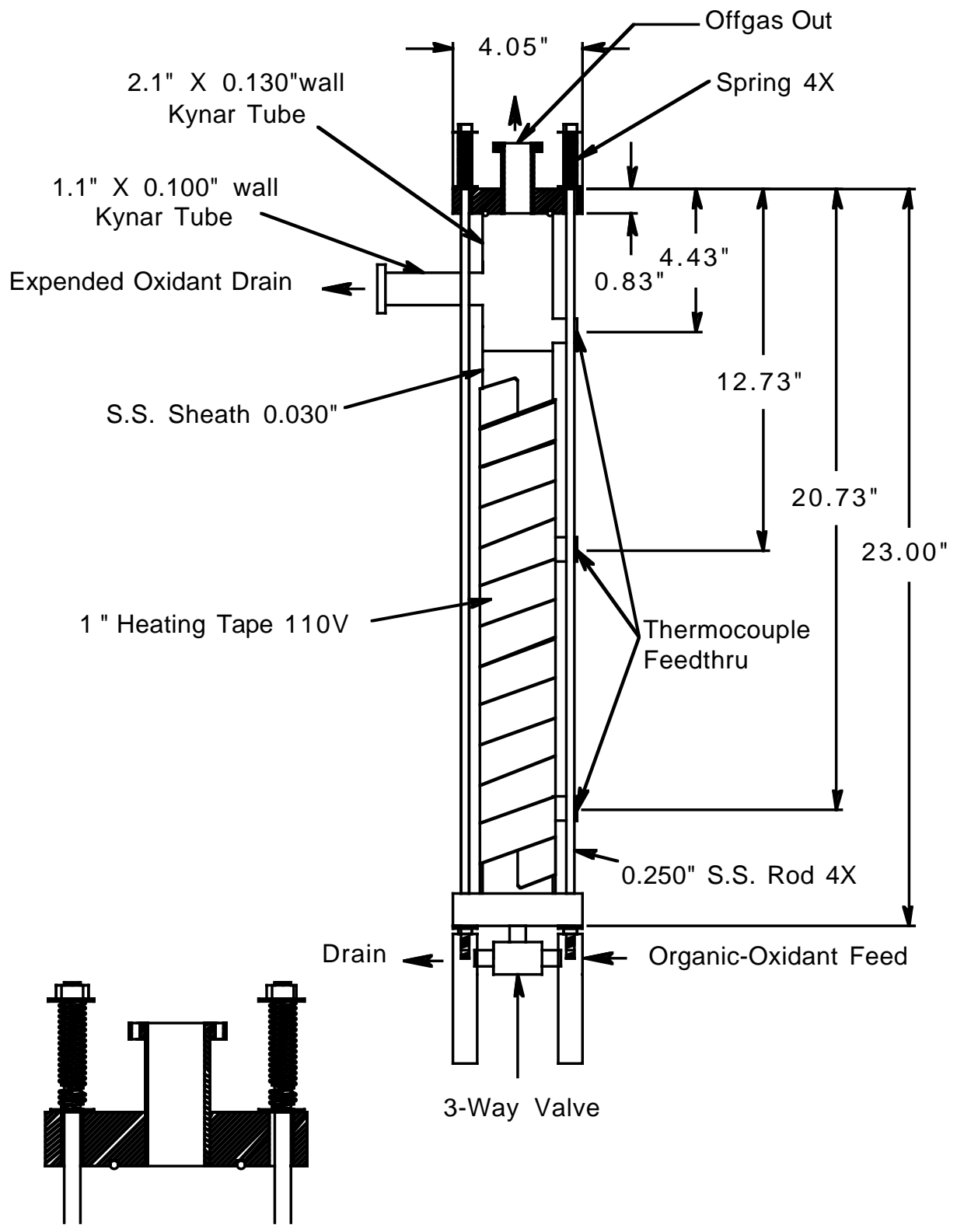


Table IV. Summary of Tests of Direct Chemical Oxidation of 1,1,1-trichloroethane Using a Vertical Packed-bed Flow Reactor.*

\begin{tabular}{|l|c|c|}
\hline \multicolumn{1}{|c|}{ Conditions $*$} & $\%-\mathbf{C O}_{2}$ & $\%-\mathbf{C l}_{2}$ \\
\hline 1. No preoxidation & & \\
\hline 1,1,1-trichloroethane & 9 & 1 \\
\hline trichloroacetic acid & 38 & 48 \\
\hline 2. Uncatalyzed preoxidation & & \\
\hline 1 day preoxidation & 18 & $<1$ \\
\hline 3 day preoxidation & 25 & $<1$ \\
\hline 3. Catalyzed preoxidation ( 100ppm Cu[II]) & & \\
\hline A. 1 day preoxidation treatment, run in packed bed reactor & 20 & $<1$ \\
\hline Aliquot of 1 day preoxidation product, oxidized in batch reactor & 20 & $<1$ \\
\hline B. 2 day preoxidation treatment & 26 & $<1$ \\
\hline Aliquot of above, run at 1/2 feed rate & 22 & $<1$ \\
\hline Aliquot of above oxidized in batch reactor & 21 & $<1$ \\
\hline C. 3. day preoxidation & 35 & 1 \\
\hline Aliquot of above oxidized in batch reactor & 39 & 5 \\
\hline
\end{tabular}

*All tests are with a $1 \%$ emulsion of 1,1,1-trichloroethane in $2.0 \mathrm{M}\left(\mathrm{NH}_{4}\right)_{2} \mathrm{~S}_{2} \mathrm{O}_{8}$ in water, using Armak 1733 surfactant and sonication (unless noted otherwise). Emulsion feed rate was $0.5 \mathrm{ml} / \mathrm{sec}$ (unless noted), and sufficient emulsion was prepared so that the total time of the emulsion feed was about 35 minutes. Feed started with top and middle portions of reactor were above $72{ }^{\circ} \mathrm{C}$; steady-state temperatures were generally in the range of $85-90{ }^{\circ} \mathrm{C}$.

A common problem with a vertical packed bed flow reactor used in this application is volatilization of unreacted chlorosolvent into the evolved carbon dioxide and oxygen offgas streams. This loss can be substantial for solvents boiling below the system operating temperature of $85-90{ }^{\circ} \mathrm{C}$, illustrated by the low conversion efficiencies (entry 1, in Table IV above). In order to lower the temperature of the process to below the boiling point, we tried a room temperature preoxidation step (to produce a soluble organic acid), and a low-temperature catalyzed oxidation using $\mathrm{Cu}(\mathrm{II})$ catalyst. Despite improvements, neither of these approaches yielded acceptable conversion efficiencies. Loss of chlorosolvent through volatilization can be avoided by oxidation in a sealed vessel. This was in fact done, producing the results given in Table III. However, scaleup of a sealed oxidation process is problematic because of the heat and gas evolution of peroxydisulfate oxidation.

While it is possible to reverse the direction of flow (increasing contact time of the gas in the reactor), a design review led to the abandonment of this configuration in favor of more tractable systems based on sequential dissolution of the chlorosolvent (via hydrolysis in a sealed vessel) followed by peroxydisulfate oxidation in a series of three cascaded continuously stirred tank reactors (CSTR).

\section{Hydrolysis of chlorosolvents}

Literature references (see list at end of this Section) show that the hydrolysis of numerous chlorinated solvents can occur, either in neutral or basic conditions, often resulting in more soluble and less volatile substances. Hydrolysis reactions can be either neutral ( $\mathrm{pH}$-independent) or base catalyzed (first order in hydroxyl concentration), depending on the strength of the $\mathrm{C}-\mathrm{Cl}$ bond and 
on steric hindrance factors. In neutral hydrolysis, hydrolysis proceeds through a simple $\mathrm{pH}$-independent ionization of the chloride group (Eq. 4):

(4)

$$
\mathrm{R}-\mathrm{Cl} \Rightarrow \mathrm{R}^{+}+\mathrm{Cl}^{-}
$$

The organic cation then reacts with water or available hydroxyl ion to form the corresponding alcohol. For organic molecules with multiple chloride groups, this hydrolysis can produce alcohols, aldehydes or ultimately organic acids. Hydrolysis can also occur by nucleophilic substitution of the chloride by the hydroxyl ion, occurring at a rate proportional to the concentration of the base. This "base catalyzed hydrolysis" is common with chlorine attached to carbon-carbon double bonds.

Jeffers [1] indicates that 1,1,1-trichloroethane (TCA) is hydrolyzed by a neutral reaction, leading after a number of steps to form acetic acid (Eq. 5):

$2 \mathrm{H}_{2} \mathrm{O}+\mathrm{H}_{3} \mathrm{CCCl}_{3} \Rightarrow \mathrm{H}_{3} \mathrm{CCOOH}+3 \mathrm{HCl}$

This reaction does not produce any chlorinated byproducts at temperatures of $65-115{ }^{\circ} \mathrm{C}$ (such as the 1,1-dichloroethene found in groundwaters polluted with TCA), although Jeffers admits that this product may be formed at low concentrations undetectable by his analysis. In ground water conditions, according to other studies, TCA undergoes a simple elimination reaction to form 1,1-dichloroethene (DCE), according to (Eq. 6):

$\mathrm{H}_{3} \mathrm{CCCl}_{3} \Rightarrow \mathrm{H}_{2} \mathrm{C}=\mathrm{CCl}_{2}+\mathrm{HCl}$

(6)

Thus about $20 \%$ of the TCA apparently is hydrolyzed to form DCE which is stable in neutral solutions, and the balance forms acetic acid. [2] The high temperature study indicates that DCE is base-catalyzed hydrolyzed by base catalysis to form acetic acid, according to (Eq. 7):

$\mathrm{H}_{2} \mathrm{C}=\mathrm{CCl}_{2}+2 \mathrm{H}_{2} \mathrm{O} \Rightarrow \mathrm{H}_{3} \mathrm{CCOOH}+2 \mathrm{HCl}$

(7)

We have elected to develop a hydrolysis pre-treatment in strong base $(\mathrm{pH}=14)$ for several fundamental reasons:

(1) The solvents targeted by the parallel QuickWin effort contain materials the hydrolysis reactions of which are clearly based catalyzed (such as dichloroethene),

(2) In principle, the hydrolysis of a wide range of mixed chlorosolvents may produce intermediates, the hydrolysis of which are base catalyzed but otherwise slow in neutral solutions,

(3) The evolution of free chloride ion would subject most hydrolysis reactor materials to stress or pitting corrosion in an acid environment; in basic media, many stainless steels such as 304 or 316L are immune to corrosion in deaerated basic media. Indeed, the last fact was found to be critical. When the amount of hydroxide was intentionally made insufficient to maintain basic conditions during hydrolysis (resulting in acidic conditions ( $\mathrm{pH}<2)$ at the end of the experiment), XRF analysis of the hydrolysis liquid showed high concentrations of stainless steel components, such as Fe, Cr, Ni, etc.

Since the kinetics of hydrolysis follow an Arrhenius temperature dependence, increasing the temperature to above ambient results in the completion of the hydrolysis 
reactions in a matter of hours. In order to prevent the volatilization of the reactants, a sealed vessel was required with a resultant above ambient pressure operation. A laboratory scale two liter hydrolysis vessel was constructed of 304SS, and the data from the hydrolysis of various chlorosolvents were collected.

Figure 3 below shows hydrolysis rates of 1,1,1-trichloroethane (TCA, or methyl chloroform) collected from various studies, together with the hydrolysis rate of dichloroethene (DCE), a base catalyzed reaction. Note that at the higher temperatures (about $100{ }^{\circ} \mathrm{C}$ ), the hydrolysis rates of TCA and DCE are on the order of magnitude of $0.01 \mathrm{~min}^{-1}{ }^{-}$-i.e., roughly comparable to the first order rate of formation of the sulfate radical anion. This suggests that the rates of hydrolysis and peroxydisulfate oxidation are comparable, and vessels for the hydrolysis and for the oxidation of hydrolysis products will be of comparable volume.

Figure 3. Hydrolysis rates for 1,1,1-trichloroethane (Jeffers data) and for DCE (base catalyzed, $\mathrm{pH}$ 14). According to Jeffers, DCE does not form above $65{ }^{\circ} \mathrm{C}$. Note that at the higher temperatures, the hydrolysis rates $\left(0.01-0.1 \mathrm{~min}^{-1}\right)$ are of the same order of magnitude as peroxydisulfate oxidation as controlled by the sulfate radical anion formation.
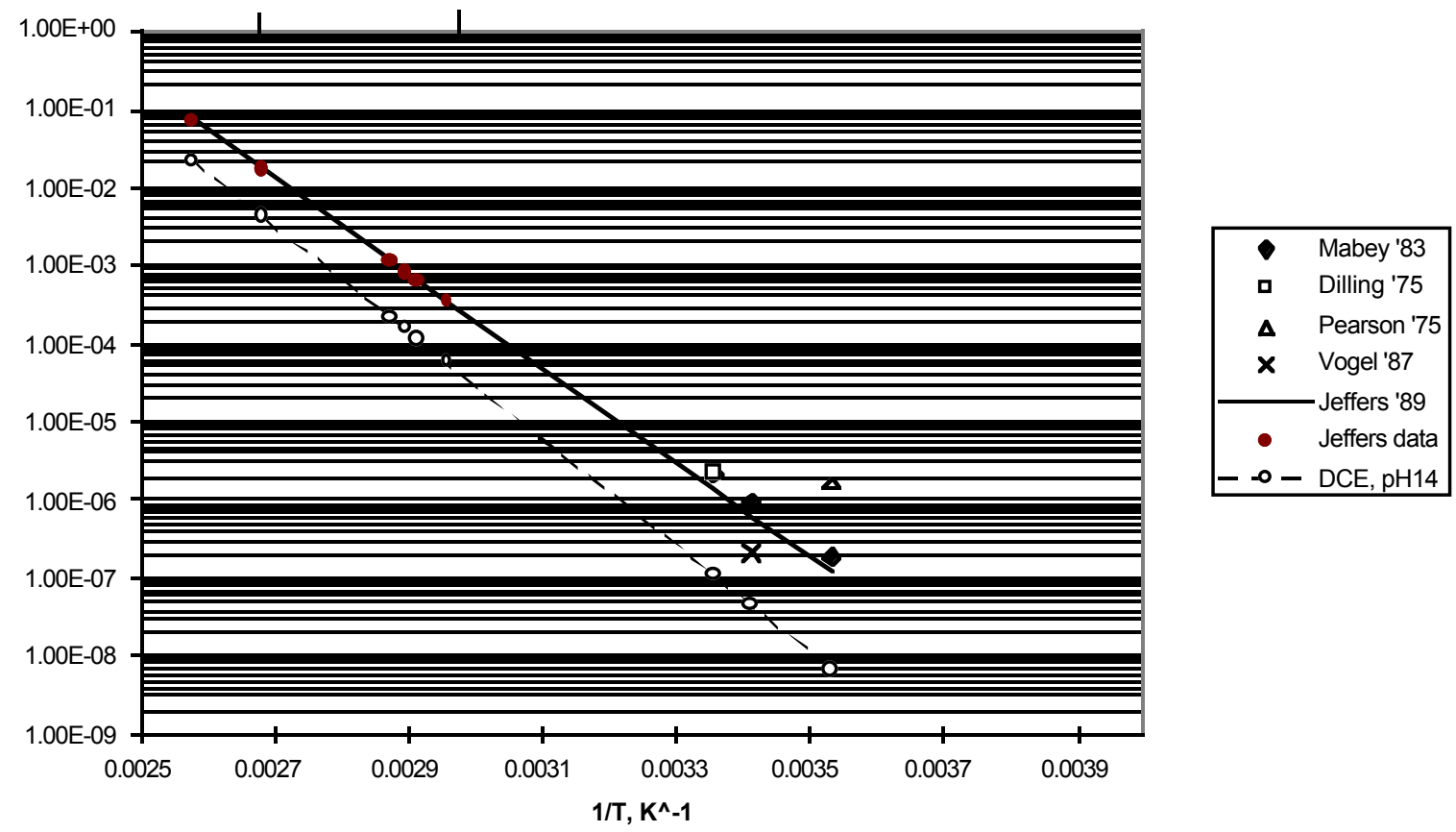
References for Hydrolysis Work (Section IV A)

1. Peter M. Jeffers, Lisa M. Ward, Lisa M. Woytowitch, and N. Lee Wolfe, "Homogeneous hydrolysis rate constants for selected chlorinated methanes, ethanes, ethenes and propanes," Environ. Sci. Technol., Vol 23(8) 1989 p. 965.

2. Timothy M. Vogel and Perry L. McCarty, "Abiotic and biotic transformations of 1,1,1-trichloroethane under methanogenic conditions," Environ. Sci. Technol. 21 1208-1213 (1987).

3. Timothy M. Vogel and Perry L. McCarty, J. of Contaminant Hydrology vol. 1 299308 (11987).

4. Timothy M. Vogel, Craig S. Criddle and Perry L. McCarty, Environ Sci. Technol. Vol. 21 (8) p 722 (1987).

5. Perry L. McCarty, "Biotic and Abiotic transformations of chlorinated solvents in ground water," (in Symposium on Natural Attenuation of Chlorinated Organics in Ground Water, Dallas TX Sept. 11-13 1996; EPA/540/R-96/509 Sept. 1996.

6. W. L. Dilling, N. Tefertiller and G. Kallos, Environ. Sci. Technol. Vol. 9 p. 833 (1975).

7. W. Mabey, T. Mill J. Phys. Chem. Ref. Data. vol. 7, p. 383 (1978).

8. C. Pearson and G. McConnell, Proc. Roy. Soc. London B189 p. 305 (1975). 


\section{Laboratory scale hydrolysis reactions}

A number of hydrolysis experiments were run at the laboratory scale to determine the rates of hydrolysis and the reaction conditions, and the results are shown in Table V. The extent of hydrolysis was measured by measuring the amount of insoluble, second phase organic material left over at the end. While this method is not extremely accurate and does not identify products specifically, it was deemed sufficient as the aim of the hydrolysis step is to produce a single liquid phase for subsequent oxidation. The rate of oxidation of organics by peroxydisulfate is very high at $80-100{ }^{\circ} \mathrm{C}$, being essentially mass transport limited, and providing a single aqueous phase is a major step towards a successful system.

Table V.

\begin{tabular}{|c|c|c|c|}
\hline Chlorosolvent(s)* & Time, Temp. of Hydrolysis & $\%$ Hydrolyzed & $\%$ Conv. to $\mathrm{CO}_{2}$ \\
\hline $1 \%$ 1,1,1-trichloroethane & $5 \mathrm{hrs} @ 100^{\circ} \mathrm{C}$ & 100 & 100 \\
\hline $3 \%$ 1,1,1-trichloroethane & $4 \mathrm{hrs} @ 120^{\circ} \mathrm{C}$ & 100 & 90 \\
\hline $10 \%$ 1,1,1-trichloroethane & 6 hrs @ $110^{\circ} \mathrm{C}$ & 100 & - \\
\hline $2 \% \mathrm{CCl}_{4}$ & $6 \mathrm{hrs} @ 112^{\circ} \mathrm{C}$ & 25 & 8 \\
\hline $\begin{array}{c}\text { 0.6\% each of: } \\
\text { 1,1,1-trichloroethane, } \\
\text { perchloroethylene } \\
\text { trichloroethylene } \\
\text { methylene chloride } \\
\text { chloroform }\end{array}$ & $6 \mathrm{hrs} @ 120^{\circ} \mathrm{C}$ & 92 & 78 \\
\hline $\begin{array}{l}1 \% \text { each of: } \\
\text { perchloroethylene } \\
\text { trichloroethylene }\end{array}$ & $5 \mathrm{hrs} @ 115^{\circ} \mathrm{C}$ & 75 & 40 \\
\hline
\end{tabular}

* The numbers refer to the volume percent loading of chlorosolvent in the hydrolysis vessel.

A GC-MS analysis of the hydrolysis product liquid showed that the hydrolysis of 1,1,1trichloroethane did not lead to a single product as would be indicated by Eqs. (4-7). Although acetic acid (or acetate ion under basic conditions) was a major product, other products were chloromethane, methylene chloride, chloroform, carbon tetrachloride and 1,1,2-trichloroethane (see Table VI). 
Table VI. GC-MS analysis results for minor products of hydrolysis step and of subsequent oxidation step for 1,1,1-trichloroethane

\begin{tabular}{|c|c|c|}
\hline Compound & $\begin{array}{c}\text { Hydrolysis } \\
\text { output }\end{array}$ & $\begin{array}{c}\text { Oxidation } \\
\text { output }\end{array}$ \\
\hline (units) & $(\%)$ & $(\mathrm{ppb})$ \\
\hline chloromethane & 0.3 & $<20^{*}$ \\
\hline methylene chloride & 9.5 & 80 \\
\hline chloroform & 9.0 & $<20^{*}$ \\
\hline 1,1,1-trichloroethane & $<0.2^{*}$ & $<20^{*}$ \\
\hline carbon tetrachloride & 0.6 & $<20^{*}$ \\
\hline 1,2 -dichloroethane & $<0.2^{*}$ & $<20^{*}$ \\
\hline $1,1,2$-trichloroethane & 0.4 & $<20^{*}$ \\
\hline chlorobenzene & $<0.2^{*}$ & $<20^{*}$ \\
\hline $1,1,2,2$-tetrachloroethane & $<0.2^{*}$ & $<20^{*}$ \\
\hline
\end{tabular}

*corresponds to method limit of detection

In addition, a dark brown solid material formed during hydrolysis which, although soluble in organic solvents, was not soluble in water. Generally, the quantity was less than about 10 vol\% of the initial chlorosolvent substrate. Through IR and GC-MS analysis, it was determined that this material was a complex mix of larger chloro-organics including 1,2,3-trichlorobenzene, trichloronaphthalene, trichloropentene, tetrachloropentane and $\mathrm{C}_{10} \mathrm{H}_{8} \mathrm{Cl}_{8}$ (Mol. Wt. 408).

It thus appears that the hydrolysis reaction involves not only the breakage of $\mathrm{C}-\mathrm{Cl}$ bonds, but also breakage of $\mathrm{C}-\mathrm{C}$ bonds and subsequent rearrangements. This result, while unexpected, is not necessarily detrimental as these materials are formed in relatively small quantities, and would be expected to be easily destroyed by peroxydisulfate in the subsequent oxidation step. As an example, the fact that many of these compounds are unsaturated or aromatic is actually an advantage in the reaction with the nucleophilic sulfate free radical anion.

In general, the hydrolysis was quantitative for a variety of organic substrates, with the notable exception of carbon tetrachloride. This material hydrolyzed only very slowly, and it is estimated that a hydrolysis reaction at the temperatures used would require weeks. Of course, increasing the temperature would decrease the time requirement, but this was not possible with our system. For all chlorinated organics, it was very important that the mixing of the hydrolysis solution be well designed, as early runs gave poor performance due to erratic mixing. The importance of proper mixing is discussed in more detail in the Integrated System discussion below (Section V).

\section{Laboratory Scale Oxidation Reactions}

The products of the hydrolysis reactions for a variety of chlorinated organics were subsequently reacted with peroxydisulfate under the nominal DCO conditions, and the extent of conversion to carbon dioxide was measured (see Table $\mathrm{V}$ above) Note that in some cases the oxidation was done under the basic hydrolysis conditions, while in others the solution was acidified using sulfuric acid before the oxidation step. There are two important differences between these two $\mathrm{pH}$ regimes. First, in basic media, carbonate is the product of oxidation and 
remains in solution until the $\mathrm{pH}$ drops below about 6 , at which point carbon dioxide is rapidly evolved in a single sharp peak (see Figure 4). The drop in $\mathrm{pH}$ from basic to acidic is due to the reduction of peroxydisulfate by the organic, with bisulfate as the product (Eq. 1). In acidic media, the oxidation evolved carbon dioxide almost immediately after reaching approximately $70{ }^{\circ} \mathrm{C}$ (see Figure 4). The second difference is that in acidic media, the organic chloride is released as chlorine, presumably through the direct recombination of chloride free radicals. In base, no chlorine gas is evolved, at least until the solution $\mathrm{pH}$ falls to values of 1-2 (again, the $\mathrm{pH}$ drop is due to the reduction of peroxydisulfate as mentioned above).

Figure 4. Evolution of carbon dioxide during the oxidation of 1,1,1-trichloroethane hydrolysis products under acidic and basic conditions. At time zero, sample was heated from ambient temperature and oxidant added.

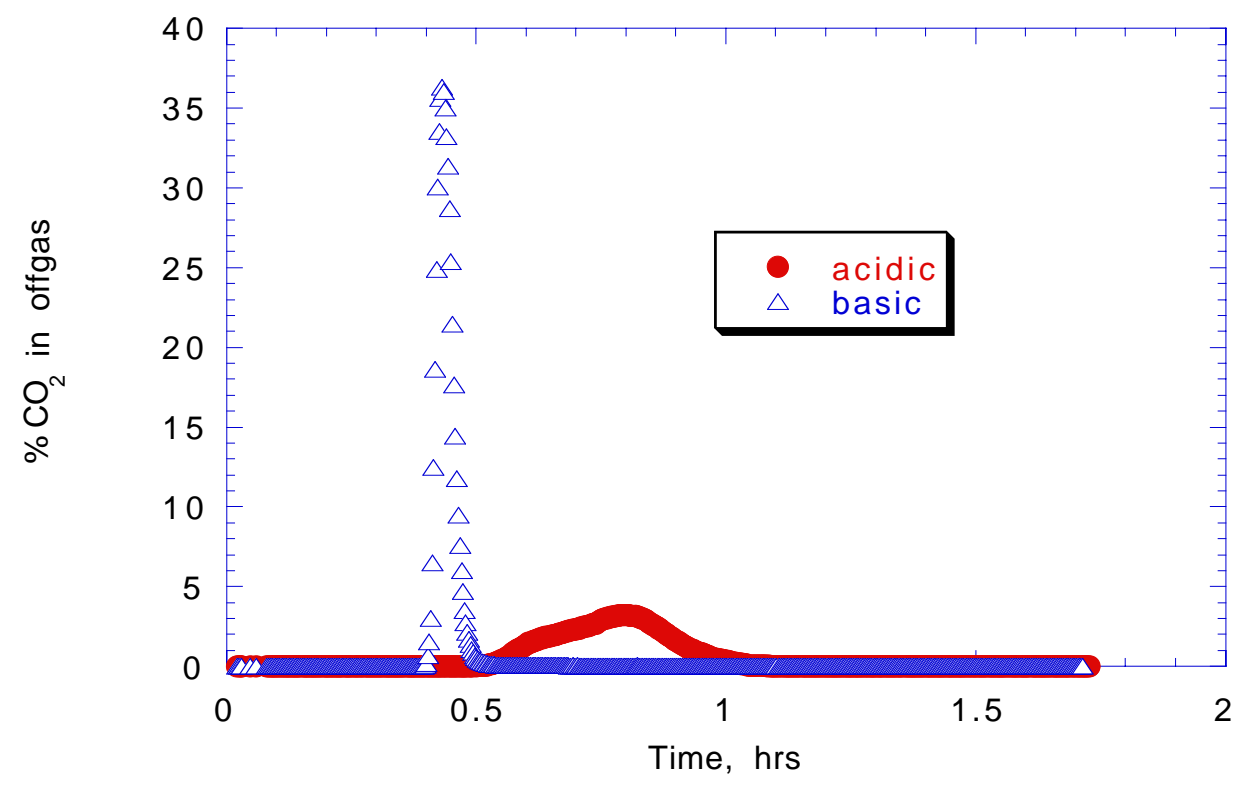

In general, the conversion of the organic to carbon dioxide was quantitative, at least within the accuracy of the described measurement technique. When the results indicated less than $100 \%$ conversion to carbon dioxide, it was believed to be due to the fact that the hydrolysis product, i.e., the oxidation feed stream, contained solid particles which were not always transferred properly into the oxidation reactor. Total Organic Carbon analyses done on the solution after oxidation always indicated essentially negligible carbon content, at least to the detection limit of the TOC analyzer (0.5 ppm, as carbon).

\section{6. $\mathrm{CCl}_{4}$ and $\mathrm{PCB}$ destruction}

Laboratory scale tests on the destruction of carbon tetrachloride by direct oxidation with peroxydisulfate at $90{ }^{\circ} \mathrm{C}$ showed that little, if any, oxidation occurred. A large excess of oxidant was added, while the offgas was continuously monitored for carbon dioxide by the IR analyzer. 
Over the course of several hours at $90{ }^{\circ} \mathrm{C}$, no significant carbon dioxide was observed. Hydrolysis of $\mathrm{CCl}_{4}$ at $100-120{ }^{\circ} \mathrm{C}$ resulted in a moderate $(\approx 25 \%)$ reduction of the organic phase volume, and a rather viscous fluid was observed. It is not known what the specific relevant reactions for this system are, but previous literature work indicated that the hydrolysis of $\mathrm{CCl}_{4}$ will occur only very slowly, even at higher temperatures.

Laboratory scale tests on the destruction of polychlorinated biphenyls are preliminary at this point. Previous work by other workers indicated that PCB's are destroyed by peroxydisulfate, and limited experimentation was done by our lab in FY97. However, it was not possible to obtain samples of pure PCB's due to California State regulatory restrictions, and thus the work in our laboratory was limited to a PCB concentration of less than $50 \mathrm{ppm}$ in water. Samples of Arochlor 1242 in water were obtained from Centre Analytical, and a surfactant was used to obtain a PCB concentration of $45 \mathrm{ppm}$ (the solubility of arochlors in water is generally much less). Because of this low concentration used for the oxidative tests, a measurement of the amount of PCB destroyed by the IR carbon dioxide analysis described above resulted in measurements that were not sufficiently above background to be conclusive (see Table VII). 
Table VII. Summary of results for PCB destruction (45 ppm Arochlor 1242 in water with a surfactant)

\begin{tabular}{|c|c|c|c|}
\hline Run \# & Conditions & total $\mathrm{ml} \mathrm{CO}_{2}$ & end TC analysis* \\
\hline 235 & Large Excess Oxidant in $1.0 \mathrm{M} \mathrm{NaOH}, 85-95^{\circ} \mathrm{C}$ & 78 & $12 \mathrm{ppm}$ \\
\hline 236 & ${ }^{\circ}$ & 79 & - \\
\hline 247 & $4.5 \mathrm{hrs}$ Hydrolysis at $100^{\circ} \mathrm{C}$, excess oxidant at $95^{\circ} \mathrm{C}$ & 77 & - \\
\hline 249 & $48 \mathrm{hrs}$ Hydrolysis at $100^{\circ} \mathrm{C}$, excess oxidant at $95^{\circ} \mathrm{C}$ & 67 & $<5 \mathrm{ppm}$ \\
\hline
\end{tabular}

Note: $106 \mathrm{mg}$ Triton $\mathrm{X}-100 /$ liter run as blank. $\mathrm{CO}_{2}$ expected $=68 \mathrm{ml} ; \mathrm{CO}_{2}$ produced $=78$ $\mathrm{ml}$.

* TC analysis judged inconclusive, as values $<10 \mathrm{ppm}$ are not reliable. Total carbon value at beginning is $25 \mathrm{ppm}$ (from Arochlor 1242) plus $63 \mathrm{ppm}$ (from surfactant), or $88 \mathrm{ppm}$ total.

In addition to the carbon dioxide analyses done for the PCB destruction tests, samples of the final solution treatment with peroxydisulfate at temperature were sent off to an independent laboratory for analysis for PCB's and dioxins/furans. These results are shown in Table VIII, and indicate that no remaining PCB's were found for three out of four samples tested. In addition, exhaustive analyses were done for dibenzo-p-dioxins and dibenzofurans, and none were found within the limits of detection. However, numerous fragments of chlorinated organics were seen, indicating that the destructive breakup of the PCB's by peroxydisulfate was chemically possible. Based on these results, it can be asserted that PCB's are oxidized by peroxydisulfate, but no data is yet available as to mechanisms, rates, or economic costs.

Table VIII. Independent laboratory analysis of final PCB solution after oxidation by peroxydisulfate $(235 \& 236$ are in basic media, $247 \& 249$ with brief hydrolysis in base, then oxidation). PCB and chloro-organic analysis is by EPA method 608; dibenzo-pdioxin and dibenzofuran analysis is by EPA method 8280 .

\begin{tabular}{|c|c|c|c|c|}
\hline Compound & 235 & 236 & 247 & 249 \\
\hline$P C B{ }^{\prime} s$ & $\mu \mathrm{g} / \mathrm{L}(\mathrm{ppb})^{*}$ & $\mu \mathrm{g} / \mathrm{L}(\mathrm{ppb})^{*}$ & $\mu \mathrm{g} / \mathrm{L}(\mathrm{ppb})^{*}$ & $\mu \mathrm{g} / \mathrm{L}(\mathrm{ppb})^{*}$ \\
\hline monochlorobiphenyl & $\mathrm{ND}(0.65)$ & $\mathrm{ND}(0.5)$ & $\mathrm{ND}(0.5)$ & $\mathrm{ND}(0.5)$ \\
\hline dichlorobiphenyl & $\mathrm{ND}(0.65)$ & $\mathrm{ND}(0.5)$ & $\mathrm{ND}(0.5)$ & 3.40 \\
\hline trichlorobiphenyl & $\mathrm{ND}(0.65)$ & $\mathrm{ND}(0.5)$ & $\mathrm{ND}(0.5)$ & 2.37 \\
\hline tetrachlorobiphenyl & $\mathrm{ND}(1.3)$ & $\mathrm{ND}(1.0)$ & $\mathrm{ND}(1.0)$ & 7.08 \\
\hline pentachlorobiphenyl & $\mathrm{ND}(1.3)$ & $\mathrm{ND}(1.0)$ & $\mathrm{ND}(1.0)$ & $\mathrm{ND}(1.0)$ \\
\hline hexachlorobiphenyl & $\mathrm{ND}(1.3)$ & $\mathrm{ND}(1.0)$ & $\mathrm{ND}(1.0)$ & $\mathrm{ND}(1.0)$ \\
\hline heptachlorobiphenyl & $\mathrm{ND}(1.9)$ & $\mathrm{ND}(1.5)$ & $\mathrm{ND}(1.5)$ & $\mathrm{ND}(1.5)$ \\
\hline octachlorobiphenyl & $\mathrm{ND}(1.9)$ & $\mathrm{ND}(1.5)$ & $\mathrm{ND}(1.5)$ & $\mathrm{ND}(1.5)$ \\
\hline decachlorobiphenyl & $\mathrm{ND}(3.2)$ & $\mathrm{ND}(2.5)$ & $\mathrm{ND}(2.5)$ & $\mathrm{ND}(2.5)$ \\
\hline & & & & \\
\hline Arochlor 1016 & $\mathrm{ND}(13)$ & $\mathrm{ND}(10)$ & $\mathrm{ND}(10)$ & $\mathrm{ND}(10)$ \\
\hline Arochlor 1221 & $\mathrm{ND}(13)$ & $\mathrm{ND}(10)$ & $\mathrm{ND}(10)$ & $\mathrm{ND}(10)$ \\
\hline Arochlor 1232 & $\mathrm{ND}(13)$ & $\mathrm{ND}(10)$ & $\mathrm{ND}(10)$ & $\mathrm{ND}(10)$ \\
\hline Arochlor 1242 & $\mathrm{ND}(13)$ & $\mathrm{ND}(10)$ & $\mathrm{ND}(10)$ & 12.9 \\
\hline Arochlor 1248 & $\mathrm{ND}(13)$ & $\mathrm{ND}(10)$ & $\mathrm{ND}(10)$ & $\mathrm{ND}(10)$ \\
\hline
\end{tabular}


DCO Final Report FY97

\begin{tabular}{|c|c|c|c|c|}
\hline Arochlor 1254 & ND (13) & ND (10) & ND (10) & ND (10) \\
\hline Arochlor 1260 & ND (13) & ND (10) & ND (10) & ND (10) \\
\hline \multicolumn{5}{|l|}{ Chloro-organics } \\
\hline 2,3-dichloro-2-methylcyclohexane & & & 150 & \\
\hline chlorocyclohexane & & & 96 & 69 \\
\hline 1,1-dichlorocyclopentane & & & 274 & \\
\hline 1,1,2,2-tetrachloroethane & & & 108 & 123 \\
\hline 2,3-dichloro-2-methylpropanal & & & 267 & 506 \\
\hline carbonic acid, methyl phenyl ester & & & 35 & \\
\hline $\begin{array}{c}2,3- \\
\text { dichlorocyclopropanecarboxylic } \\
\text { acid }\end{array}$ & & & 241 & 37 \\
\hline 3-chlorocyclohexene & & & 31 & \\
\hline trans-1,2-dichlorocyclohexane & & & 54 & \\
\hline 1,1-dichloro-2-ethenylcyclopropane & & & 37 & \\
\hline $\begin{array}{l}\text { chloroacetyl chloride } \\
\end{array}$ & & & 50 & 50 \\
\hline chloromethoxymethane & & & 61 & 59 \\
\hline 1,1-dichloro-2-methylcyclopropane & & & $\overline{594}$ & 470 \\
\hline 1,4-dichloro-2-butene & & & 84 & 63 \\
\hline 1,1,1,3-tetrachloropropane & & & 61 & \\
\hline 5,6-dimethoxyphthalaldehydic acid & & & 50 & \\
\hline 2,3-dichlorobutane & & & & 311 \\
\hline 1,3-dichloro-2-butene & & & & 40 \\
\hline cis-1,2-dichlorocyclopentane & & & & 894 \\
\hline trans-1,2-dichlorocyclopentane & & & & 65 \\
\hline s-dichloroethyl ether & & & & 73 \\
\hline $\begin{array}{c}\text { 2,3-dichlorobutanoic acid, methyl } \\
\text { ester }\end{array}$ & & & & 73 \\
\hline 7-chloro-3-heptyne & & & & 51 \\
\hline Dioxins and Furans & ng/L (ppt)* & & & $\mathrm{ng} / \mathrm{L}(\mathrm{ppt})^{*}$ \\
\hline $2,3,7,8-\mathrm{TCDD}$ & ND $(0.3)$ & & & ND $(0.09)$ \\
\hline $1,2,3,7,8-\mathrm{PeCDD}$ & ND (6.4) & & & ND (0.2) \\
\hline $1,2,3,4,7,8-\mathrm{HxCDD}$ & ND (4.0) & & & ND (0.2) \\
\hline $1,2,3,6,7,8-\mathrm{HxCDD}$ & $\mathrm{ND}(1.4)$ & & & $\mathrm{ND}(0.1)$ \\
\hline $1,2,3,7,8,9-\mathrm{HxCDD}$ & ND (2.0) & & & $\mathrm{ND}(0.2)$ \\
\hline $1,2,3,4,6,7,8-\mathrm{HpCDD}$ & ND (4.1) & & & ND (0.2) \\
\hline $1,2,3,4,6,7,8,9-\mathrm{OCDD}$ & ND (4.4) & & & ND (0.3) \\
\hline $2,3,7,8-\mathrm{TCDF}$ & ND (0.4) & & & $\mathrm{ND}(0.07)$ \\
\hline $1,2,3,7,8-\mathrm{PeCDF}$ & ND (5.6) & & & ND (0.09) \\
\hline $2,3,4,7,8-\mathrm{PeCDF}$ & ND (8.0) & & & ND (0.09) \\
\hline $1,2,3,4,7,8-\mathrm{HxCDF}$ & ND (7.0) & & & ND (0.1) \\
\hline $1,2,3,6,7,8-\mathrm{HxCDF}$ & $\overline{N D(6.5)}$ & & & $\begin{array}{l}\mathrm{ND}(0.1) \\
\end{array}$ \\
\hline
\end{tabular}


DCO Final Report FY97

\begin{tabular}{|c|c|c|}
\hline $2,3,4,6,7,8-\mathrm{HxCDF}$ & ND (4.2) & $\mathrm{ND}(0.2)$ \\
\hline $1,2,3,7,8,9-\mathrm{HxCDF}$ & $\mathrm{ND}(3.8)$ & $\mathrm{ND}(0.2)$ \\
\hline $1,2,3,4,6,7,8-\mathrm{HpCDF}$ & ND (1.4) & $\mathrm{ND}(0.2)$ \\
\hline $1,2,3,4,7,8,9-\mathrm{HpCDF}$ & $\mathrm{ND}(4.3)$ & $\mathrm{ND}(0.2)$ \\
\hline $1,2,3,4,6,7,8,9-\mathrm{OCDF}$ & ND (2.5) & $\mathrm{ND}(0.3)$ \\
\hline
\end{tabular}

$* \mathrm{ND}=$ "Not Detected"; number in parenthesis corresponds to limit of detection

Longer term hydrolysis of PCB's, or at higher temperatures, followed by oxidation (as described for the other chlorosolvents above) remains a viable option, but this work was not completed in FY97. In order to provide more definitive testing, it is suggested that the oxidative destruction tests be performed at a laboratory better equipped to work with higher concentrations of PCB's. Obtaining ES\&H and regulatory approval to do the work at our current facilities at LLNL is not believed to be viable due to the time and effort required.

\section{Preliminary Tests on Sludge and Soil Simulants.}

According to Peyton, nearly every collision of an organic molecule with the sulfate radical anion produces a charge transfer reaction. Accordingly, one suspects that the direct chemical oxidation process would oxidize dissolved organic material in the interstices between soil particles with similar results as obtained in a large volume of free liquid.

To test this hypothesis, we conducted a number of 1-liter scale experiments in sludge and soil simulants, using a bottle rotator to provide continuous mixing. Three different types of soils were used in the first experiment: sea sand, granitic sand, and montmorillonite clay, in amounts of 16, 14 and 12 grams, respectively. The organics introduced into the above mixtures included ethylene glycol, 1,3-dichloro-2-propanol (DCP) and phenol. The oxidant solution used was $2 \mathrm{~N}$ $\left(\mathrm{NH}_{4}\right)_{2} \mathrm{~S}_{2} \mathrm{O}_{8}$ in $0.1 \mathrm{M} \mathrm{H}_{2} \mathrm{SO}_{4}$. This amount was a ten-fold excess more (in equivalents) than the organic. The oxidizer and one organic were introduced to each soil sample just prior to placement in an agitating waterbath, which shook the samples at $295 \mathrm{rpm}$ for 1 hour at $85^{\circ} \mathrm{C}$. Samples were left overnight at room temperature so the solid material could settle out. The liquid portion was then decanted and sent for TOC (total organic carbon) analysis. The soil was also pyrolyzed to determine the quantity of organic that might still be bound to the soil.

In a second experiment, an inorganic sludge material was used that was produced here on site from a recipe received from INEL (Idaho National Engineering Laboratory). The composition of the sludge was as follows: $\mathrm{Fe}_{2} \mathrm{O}_{3}(16.5 \%), \mathrm{Mg}(\mathrm{OH})_{2}(8.03 \%), \mathrm{CaSO}_{4}-2 \mathrm{H}_{2} \mathrm{O}(14.34 \%)$, $\mathrm{Ca}(\mathrm{OH})_{2}(24.34 \%), \mathrm{KNO}_{3}(28.53 \%)$, and diatomaceous earth $(8.25 \%)$. This material was first mixed in the proper proportions and then crushed to uniformity with a mortar and pestle. One sample of dehydrated montmorillonite clay was also used to determine whether removing the water from the clay would help organics adhere more tightly to it.

For the experiment, there were three samples of sludge, and one sample of montmorillonite; each sample contained 15 grams. Since the sludge solutions are slightly basic, the oxidizer used in these experiments was a $4 \mathrm{~N}$ solution of $\mathrm{Na}_{2} \mathrm{~S}_{2} \mathrm{O}_{8}$. Ammonium peroxydisulfate is not suitable in basic solutions as ammonia gas would be given off. Before use, the clay was dehydrated in a drying oven at $125{ }^{\circ} \mathrm{C}$ overnight. As in the first set of experiments above, the amount of organic (ethylene glycol, dichloropropanol, or phenol) introduced into each clay or sludge sample was one-tenth the amount of equivalents of oxidant used. The organic was put on the clay or sludge sample and allowed to sit for 1.5 hours to allow sufficient time for the adsorption of the organic onto the material to occur to the maximum extent possible. The oxidant 
was then added to all samples just before they were placed in the agitating waterbath, which subsequently ran for 1 hour at $85{ }^{\circ} \mathrm{C}$ at $275 \mathrm{rpm}$. When the experiment was completed, the samples were allowed to sit at room temperature overnight. Neither the clay nor sludge material settled out to any great extent, and so the samples were centrifuged the next day. The liquid portion was sent for TOC analysis, while the solid portion was sent for pyrolysis.

The results from the first set of experiments are shown in Table IX. All TOC samples were initially done with a 1:25 dilution, but because the lower limit of the analysis equipment is 1 ppm (after dilution), results of around $25 \mathrm{ppm}$ can be considered background. Some samples were redone with no dilution and these had a remaining TOC reading between 1.5 and 3 ppm, indicating that nearly all the organic introduced into the soil samples was destroyed.

Table IX. Oxidation of ethylene glycol, phenol and 1,3-dichloropropanol (DCP) in simulated soils and sludge backgrounds.

\begin{tabular}{|c|c|c|c|c|c|}
\hline \multirow{2}{*}{$\begin{array}{c}\text { Soil/Sludge } \\
\text { Material } \\
\end{array}$} & \multirow[t]{2}{*}{ Oxidant } & \multirow[t]{2}{*}{ Organic } & \multirow{2}{*}{$\begin{array}{c}\text { Initial conc. } \\
(\mathrm{ppm})\end{array}$} & \multicolumn{2}{|c|}{ Final conc. $(\mathrm{ppm})$} \\
\hline & & & & $\begin{array}{c}\text { (samples } \\
\text { neat) }\end{array}$ & 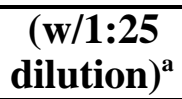 \\
\hline $\mathrm{SiO}_{2}$ (sea sand) & $\begin{array}{l}2 \mathrm{~N}\left(\mathrm{NH}_{4}\right)_{2} \mathrm{~S}_{2} \mathrm{O}_{8} \\
\text { in } 0.1 \mathrm{M} \mathrm{H}_{2} \mathrm{SO}_{4}\end{array}$ & $\begin{array}{c}\text { Ethylene } \\
\text { glycol }\end{array}$ & 1250 & 1.58 & 22 \\
\hline $\mathrm{SiO}_{2}$ & " & DCP & 1600 & 3.00 & 24 \\
\hline $\mathrm{SiO}_{2}$ & $"$ & Phenol & 675 & 1.76 & 23 \\
\hline Granitic sand & $"$ & $\begin{array}{c}\text { Ethylene } \\
\text { glycol }\end{array}$ & 1250 & 1.04 & 23 \\
\hline Granitic sand & " & DCP & 1600 & 2.00 & 25 \\
\hline Granitic sand & $"$ & Phenol & 675 & 2.00 & 24 \\
\hline $\begin{array}{l}\text { Montmorillonite } \\
\text { (clay) }\end{array}$ & $"$ & $\begin{array}{c}\text { Ethylene } \\
\text { glycol }\end{array}$ & 1250 & $\begin{array}{l}\text { Insuff. } \\
\text { sample }\end{array}$ & 24 \\
\hline Montmorillonite & $"$ & $\mathrm{DCP}$ & 1600 & " & 30 \\
\hline Montmorillonite & $"$ & Phenol & 675 & $"$ & 22 \\
\hline Montmorillonite & $\begin{array}{c}4 \mathrm{~N} \mathrm{Na}_{2} \mathrm{~S}_{2} \mathrm{O}_{8} \text { in } \\
\text { water }\end{array}$ & DCP & 3200 & 0.31 & \\
\hline Inorganic sludge & " & $\begin{array}{l}\text { Ethylene } \\
\text { glycol }\end{array}$ & 2500 & 11 & \\
\hline Inorganic sludge & $\pi$ & $\mathrm{DCP}$ & 3200 & 11 & \\
\hline Inorganic sludge & $"$ & Phenol & 1350 & 11 & \\
\hline
\end{tabular}

${ }^{a}$ In diluted samples, final concentration should be divided by 25 to obtain projected residual concentration.

\section{The electrolysis of simulated DCO products}

This work was planned largely complete in the previous work session (FY1996). It is included here for purposes of closure on the issue of recyclability of the product sulfates.

An existing electrolysis cell (designed for sustained operation at 10-20 A) was upgraded for operation at $100 \mathrm{~A}$. This upgraded system was designed to investigate the efficiency of the recycling of sulfate to peroxydisulfate, when the ammonium hydrogen sulfate was contaminated with large amounts of inorganic substances resulting from oxidation of wastes (such as chlorides, 
nitrates, and phosphates). The pre-existing system (Figure 5) was upgraded by replacing the single Pt-wire electrode (supported on a Teflon tube) with six water-cooled anodes operating in parallel, and by increasing the number of graphite cathodes from 3 to 6 . Each water cooled anode unit consisted of (0.051 in dia.) Pt wire wound around the cooling tube.

Solutions of acidified ammonium sulfate $\left(2.65 \mathrm{M} \mathrm{H}_{2} \mathrm{SO}_{4}+1.59 \mathrm{M}\left(\mathrm{NH}_{4}\right)_{2} \mathrm{SO}_{4}\right)$ were electrolyzed at 0.5 or $1 \mathrm{~A} / \mathrm{cm}^{2}$ with and without high concentrations of inorganic contaminants expected to be entrained in the oxidant recycle loop following destruction of chlorinated, nitrated or phosphated wastes. The baseline, or control solution, consisted of the sulfuric acid/ ammonium sulfate solution with additives normally used in industrial cells: (1.5 grams of ammonium nitrate $\left(7.8 \times 10^{-3} \mathrm{M}\right)$ and 0.8 grams of potassium thiocyanate $\left(3.4 \times 10^{-3} \mathrm{M}\right)$. To this baseline, we added chloride, nitrate, or phosphate to make $50 \mathrm{mM}$ solutions. All experiments were conducted at a fixed total current of $100 \mathrm{~A}$ with cell voltages between 6 and $10 \mathrm{~V}$, and the total area of exposed platinum wire was adjusted for current densities at two levels: 0.6 and $1 \mathrm{~A} / \mathrm{cm}$. The high specific amperage ( $80 \mathrm{~A} /$ liter) is typical of industrial cells and sufficiently large to minimize the extent of the chemical reduction of peroxydisulfate at the platinum electrode.

Starting with 2.4 liters total (equally divided between anolyte and catholyte), $1 \mathrm{ml}$ of solution was taken every 15 minutes for a total of $2 \mathrm{~h}$. The solution was diluted and reduced with $0.1 \mathrm{~N} \mathrm{Fe}$ (II) solution, and then back titrated with a standardized solution of $\mathrm{KMnO}_{4}$ until a colordetermined endpoint. Approximately $5 \mathrm{~min}$. was allowed for the total oxidation of $\mathrm{Fe}(\mathrm{II})$ by peroxydisulfate, which is slow at room temperature.

The plot of oxidant concentration against time can be related to current efficiency ' $\mathrm{e}$ ' through a variation of Faraday's law:

$$
\mathrm{e}=[\mathrm{Ox}(\mathrm{t})] \mathrm{V}_{\mathrm{a}} /(\mathrm{It} / \mathrm{F})
$$

This efficiency is simply the ratio of equivalents of oxidant formed in solution of volume $\mathrm{V}_{\mathrm{a}}$ to the charge passed expressed in equivalents through the Faraday constant, F (96500 coul/equiv).

In Figures 6 and 7, the buildup of oxidant is plotted against time for fixed currents of 100 $\mathrm{A}$ and fixed anolyte volumes (1.2 liters). Occasional negative values of oxidant are likely the results of reduced accuracy of the back titration technique at very low oxidant concentrations. In all cases, the best reported industrial efficiencies of $80 \%$ are found at concentrations up to $1.5-2 \mathrm{~N}$, depending on current density and temperature. Limitations in the capacity of our cooling system (which effected a stable operating temperature of $25{ }^{\circ} \mathrm{C}$ at the high current density) prevented chilling this solution to $14{ }^{\circ} \mathrm{C}$ where higher steady state oxidant concentrations are expected. In no case was there a clear deterioration of efficiency due to the presence of chloride, phosphate or nitrate. 
Figure 5. Electrolysis cell used for recycling of peroxydisulfate

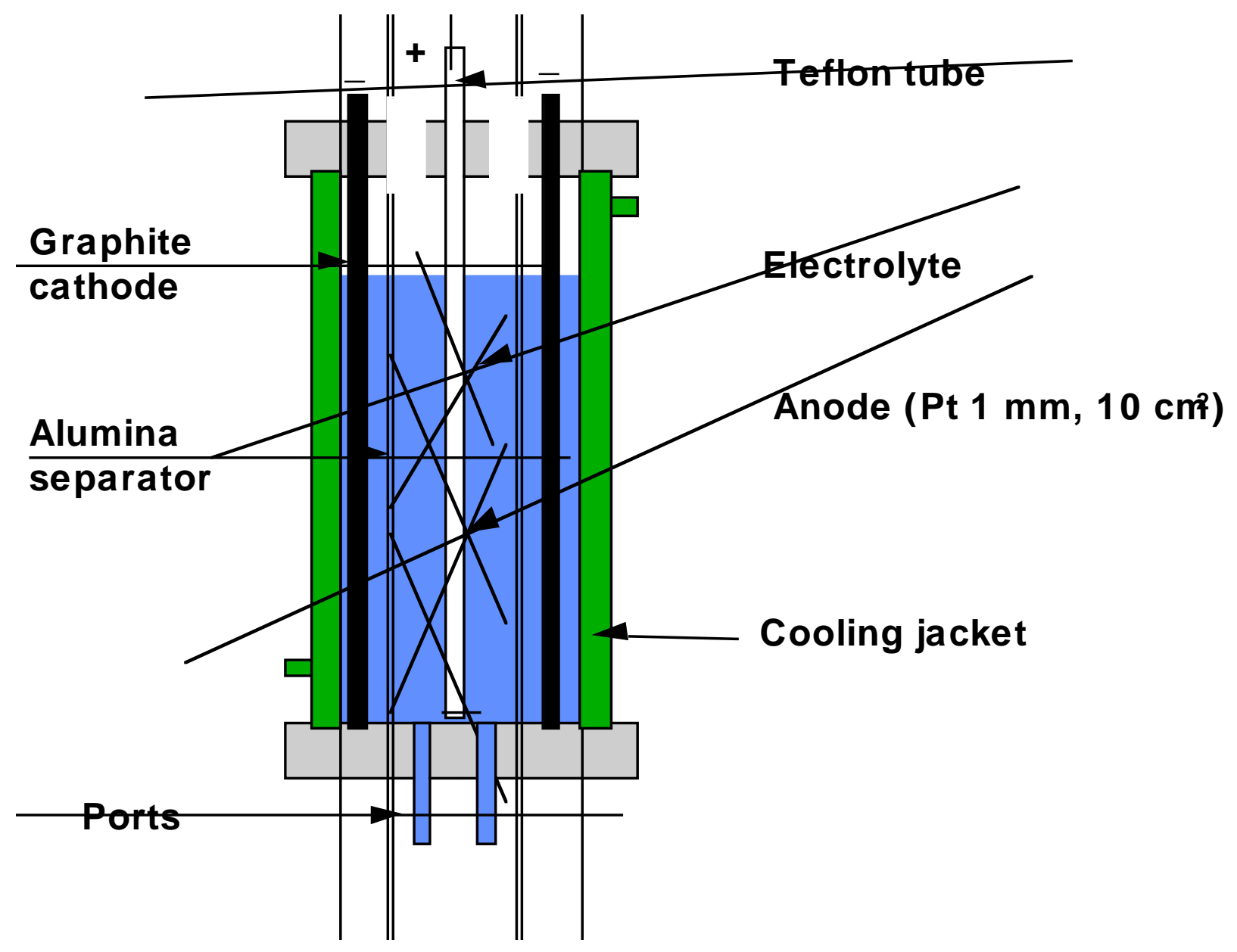


Figure 6. Oxidation of ammonium sulfate at low current density $\left(0.4 \mathrm{~A} / \mathrm{cm}^{2}\right)$ at ampere density of $80 \mathrm{~A} /$ liter for baseline acidified sulfate solution with $0.05 \mathrm{M}$ amounts of chloride, phosphate, and nitrate. Broken line is for efficiency of $80 \%$.

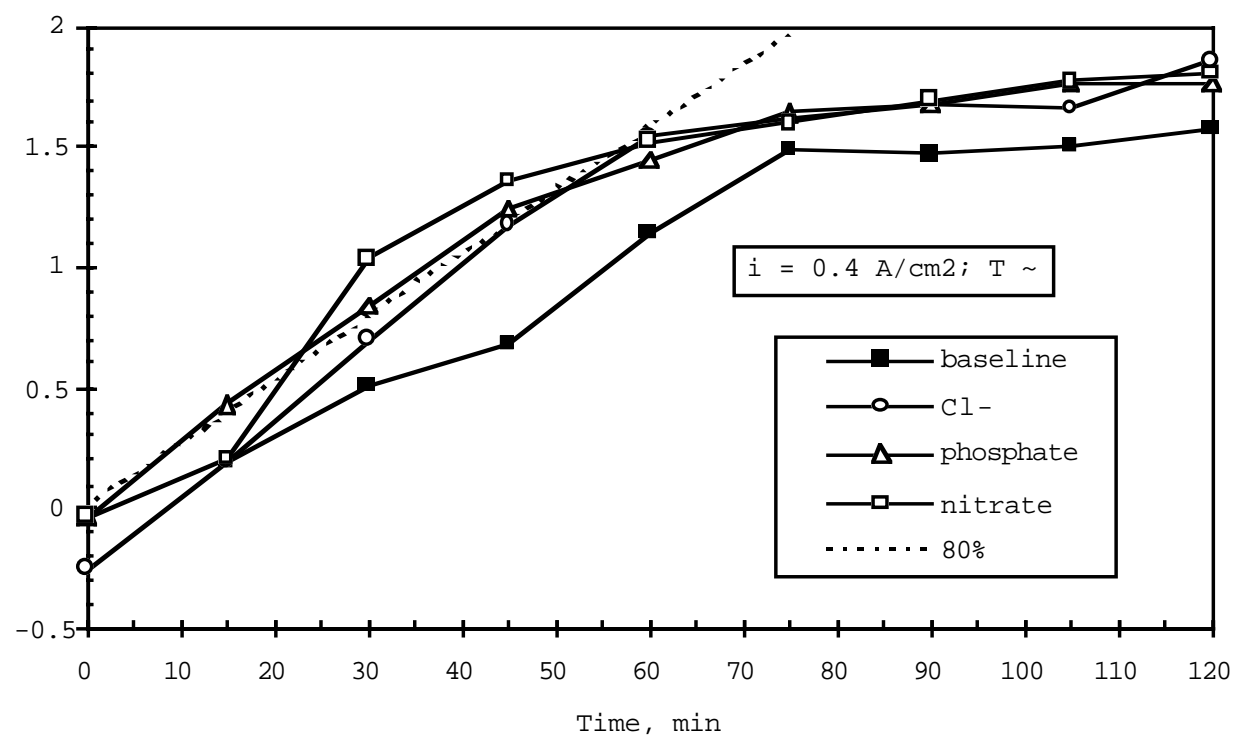

Figure 7. Oxidation of ammonium sulfate at high current density $\left(1 \mathrm{~A} / \mathrm{cm}^{2}\right)$ at ampere density of $80 \mathrm{~A} /$ liter for baseline acidified sulfate solution with $0.05 \mathrm{M}$ amounts of chloride, phosphate, and nitrate. Broken line is for efficiency of $80 \%$.

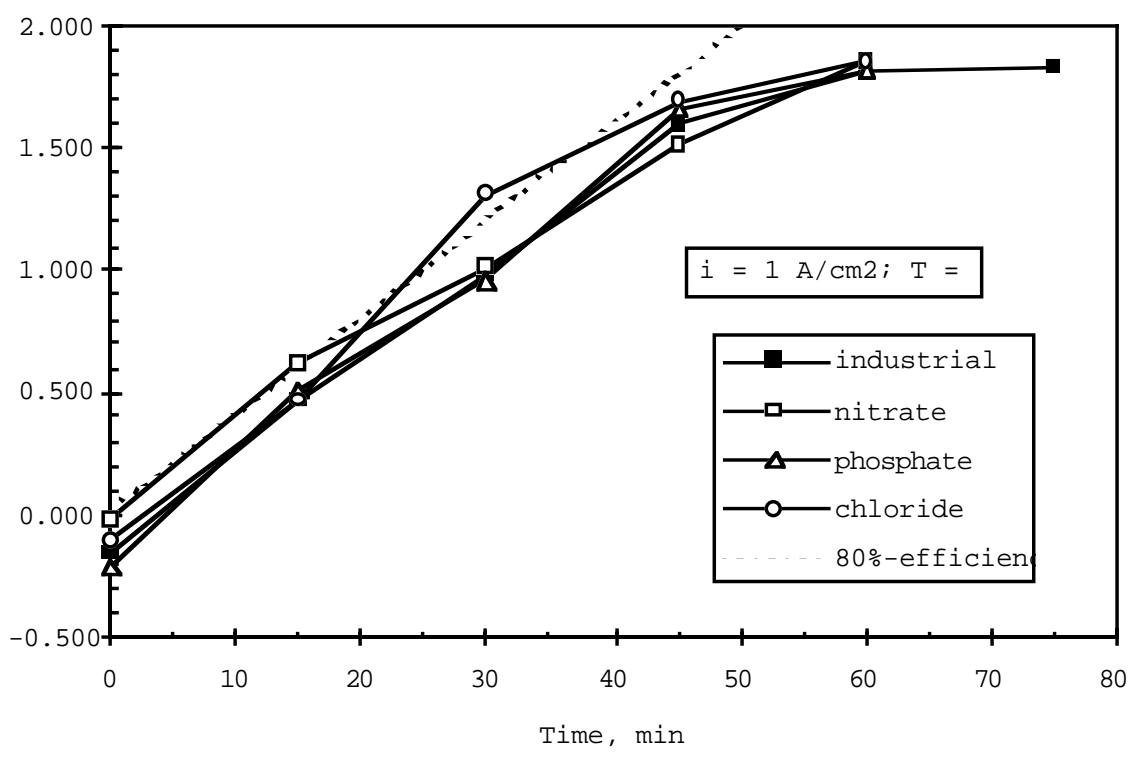




\section{B. Economic Analysis}

The cost of organics destruction using the DCO technology will depend heavily on the nature of the waste stream being treated, and whether or not the expended oxidant is electrochemically recycled. With regard to the former, costs will be minimized when treating easily oxidizable organics in neat form. The presence of significant amounts of water in the waste stream (greater than approximately 50\%) will increase the amount of peroxydisulfate required, as water is also capable of reducing this oxidant, albeit more slowly than the organics. Heavily chlorinated organics will require more oxidant due to the oxidation of organo-chlorine to free chlorine gas. Also, if the waste matrix contains a substantial amount of non-hazardous organics, such as would be the case with the humic acids in contaminated soils, then more peroxydisulfate is required due to the competing oxidations of these matrix components.

For the destruction of neat organics, the cost of DCO can be estimated using the following values (see Table X):

Table X.

\begin{tabular}{|c|c|}
\hline Factor & Value \\
\hline 1. Cost of Peroxydisulfate purchased in bulk & $\$ 0.73 / \mathrm{lb}$ \\
\hline 2. Electrons required per carbon atom in the organic & 4 \\
\hline 3. Destruction efficiency & $80 \%$ \\
\hline & 5 volts \\
\hline 4. Electrolysis cell voltage & $80 \%$ \\
\hline 5. Electrolysis efficiency & $\$ 0.06 / \mathrm{kWh}$ \\
\hline 6. Cost of electricity & $\$ 120 /$ day \\
\hline 2. Capital amortization & interest \\
\hline 9. Profit and GS\&A & $30 \%$ \\
\hline 10. Plant capacity factor & $80 \%$ \\
\hline
\end{tabular}

If the expended oxidant is not recycled, then the cost of DCO is $\$ 79 / \mathrm{kg}$ carbon destroyed. If the peroxydisulfate is recycled, then the energy cost is $\$ 4 / \mathrm{kg}$ carbon destroyed. Adding in the other factors listed above, the total cost for DCO destruction and recycle is $\$ 10.4 / \mathrm{kg}$ carbon destroyed.

\section{Cost Account Status}

All work completed and all accounts closed. See budget section below (Section VIII).

Milestones Title

C1. Process defined for highly chlorinated and volatile wastes
Completion Date

April 1997

Collaborators and Principal Performers

PI: John F. Cooper, Lawrence Livermore National Laboratory

co-PI: Bryan Balazs, Lawrence Livermore National Laboratory

Consultant: Gary Peyton, Illinois State Water Survey, Champaign IL

Prospective Advisor: Robert Huie, NIST, Gathersberg 
DCO Final Report FY97 38 


\section{SUBTASK II.}

\section{A. Summary of Results}

The data obtained at the laboratory scale for Subtask I above were used to design and build the Integrated System shown in Figure 8 (pictures in Appendix B). This system has been tested on 1,1,1-trichloroethane, at both 3 and 10 vol\% loading, with and without a sludge matrix, and on a mixture of chlorosolvents. The parameters for the completed runs are given in Table XI.

Table XI. Integrated DCO System test parameters and data.

\begin{tabular}{|c|c|c|c|}
\hline Run \# & Organic Substrate(s) $^{1}$ & Time, Temp. of Hydrolysis & DRE \\
\hline 1 & test (ethylene glycol) & not applicable & $>90 \%$ \\
\hline 2 & test (acetic acid) & not applicable & $>97 \%$ \\
\hline 3 & test (acetic acid) & not applicable & $>99 \%$ \\
\hline 4 & $3 \% 1,1,1$-trichloroethane & $4 \mathrm{hrs} @ 120{ }^{\circ} \mathrm{C}^{2}$ & $>98 \%$ \\
\hline 5 & $3 \% 1,1,1$-trichloroethane & $4 \mathrm{hrs} @ 120{ }^{2}$ & $>99.5 \%$ \\
\hline 6 & $3 \% 1,1,1$-trichloroethane & $2.5 \mathrm{hrs} @ 110^{\circ} \mathrm{C}$ & see text \\
\hline 7 & $\begin{array}{c}\text { mixture of: } \\
\text { 1,1,1-trichloroethane, } \\
\text { perchloroethylene } \\
\text { trichloroethylene } \\
\text { methylene chloride } \\
\text { chloroform }\end{array}$ & $2.5 \mathrm{hrs} @ 110^{\circ} \mathrm{C}$ & \\
\hline 8 & $10 \% 1,1,1$-trichloroethane & & see text \\
\hline 9 & $\begin{array}{c}3 \% 1,1,1 \text {-trichloroethane } \\
\text { in simulated sludge matrix }\end{array}$ & $4 \mathrm{hrs} @ 110^{\circ} \mathrm{C}$ & see text \\
\hline
\end{tabular}

${ }^{1}$ The numbers refer to the volume percent loading of chlorosolvent in the hydrolysis vessel.

${ }^{2}$ Done with multiple batches of the lab-scale hydrolysis vessel.

Figure 8 shows the integrated bench scale system which includes a hydrolysis vessel, a feed tank, a 3-stage continuous stirred tank reactors (CSTR), an off-gas treatment tank, an oxidant make-up tank, as well as a surge tank. An electrolysis cell can be included in the process as a secondary equipment for the regeneration of oxidant. The hydrolysis vessel was made of 316L stainless steel with an internal volume of 73.2 liters. This vessel was equipped with a $5 \mathrm{~kW}$ immersion heater and a double mechanical seal mixer with a seal rated at 200 psig and $150{ }^{\circ} \mathrm{C}$. This vessel was designed for a maximum operating pressure of $100 \mathrm{psig}$ and maximum operating temperature of $120^{\circ} \mathrm{C}$; reference Mechanical Engineering Safety Note \#97-044-OA. An electronic pressure transducer was fitted and a pressure relief valve was fitted and set to $120 \mathrm{psig}$. Fluids were pumped in and out of the vessel using appropriate valving and peristaltic pumps. The organic substrate was pumped in first, followed by the appropriate quantity of sodium hydroxide solution. Following a hydrolysis run, the hydrolyzed solution was then transferred to a 30 gallon polypropylene feed tank where oxidant is added at room temperature. Excess oxidant is needed for more favorable kinetics and throughput. The solution is then cascaded through the oxidation system.

The oxidation system consisted of three CSTR's. These reactors were glass and of an internal volume of 17 liters. The flow rate and residence time in the CSTR can be carefully controlled such that desirable destruction removal efficiencies (DRE's) can be achieved. Samples 
are taken from each stage for analyses of TOC and oxidant. The 3rd stage CSTR is used as a polisher where oxidant concentration and operating temperature vary in order to completely destroy all the organics in the solution. The organic-free solution can then be discharged into a 55 gallon surge tank or passed to an electrolysis cell for the regeneration of oxidant to reduce cost and minimize the oxidant consumption. The offgas from each CSTR was pumped through a condenser, and then each output was combined into one common stream. A slipstream of this was passed to the carbon dioxide analyzer setup used in the laboratory scale experiments above, while the flow rates of the slipstream and of the main stream were measured continuously. Liquid samples for analysis were taken from each CSTR output as needed.

Figure 8. Process Flow Diagram for Integrated System

\section{Process Flow Diagram For DCO Integrated System}

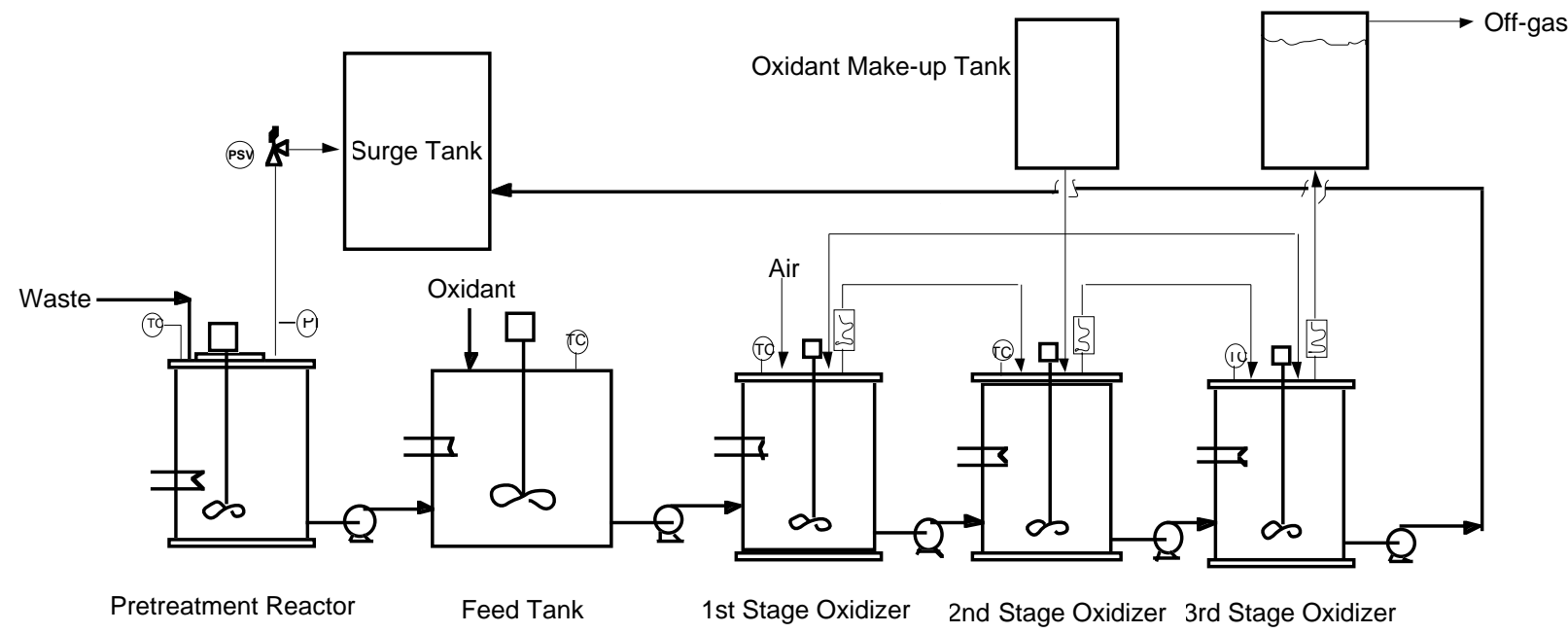

\begin{tabular}{|l|c|}
\hline $\begin{array}{l}\text { Originator } \\
\text { reer nsu }\end{array}$ & $\begin{array}{c}\text { Direct Chemical Oxidation System } \\
\text { MWFA, Task II }\end{array}$ \\
\hline $\begin{array}{l}\text { Rev.: 0 } \\
\text { vare o/yI }\end{array}$ & \\
\hline & C\&MS/EP \\
& $\begin{array}{l}\text { Lawrence Livermore National } \\
\text { Laboratory, Livermore, CA }\end{array}$ \\
\cline { 2 - 2 } & \\
\hline
\end{tabular}

Mixing the reaction fluid in each DCO reactor is easily achieved since it is a single homogeneous phase. Mixing speed was maintained at above $100 \mathrm{rpm}$ to obtain turbulent flow in order to reduce mass transfer resistance and improve the process kinetics. The required mixing time is fairly short ( $<20$ seconds) for incoming liquids comparing to the residence time which was kept at above 50 minutes. For mixing the two-phase liquids in the hydrolysis vessel, a properly designed impeller and high mixing speed are required to minimize mass transfer resistance and 
increase interfacial surface area for faster hydrolysis. The mixing was achieved with a 5 inch high shear impeller (Shearmor impeller by MixMor) at $800 \mathrm{rpm}$. The combination of powerful mixing and a high reaction temperature significantly reduced the time required for complete hydrolysis from years to several hours.

As the hydrolysis of the volatile chlorosolvents proceeds, the pressure inside the hydrolysis tank will decrease assuming that the products or intermediates formed are less volatile than the starting material. For hydrolysis reactions of materials such as 1,1,1-trichloroethane, this was expected to be the case as acetic acid is a primary product of the reaction. This was verified experimentally as shown in Figure 9, where the pressure and temperature of the hydrolysis vessel are plotted versus time. For the first 3 hours, both pressure and temperature increase as the reactor is heating up. There are slight increases in pressure for 3 or more hours, and then the pressure falls off rapidly. The increase in pressure for the intermediates when the temperature is relatively constant is presumably due to the formation of more volatile intermediates.

Figure 9. Pressure and Temperature vs. Time for Hydrolysis of 1,1,1-trichloroethane

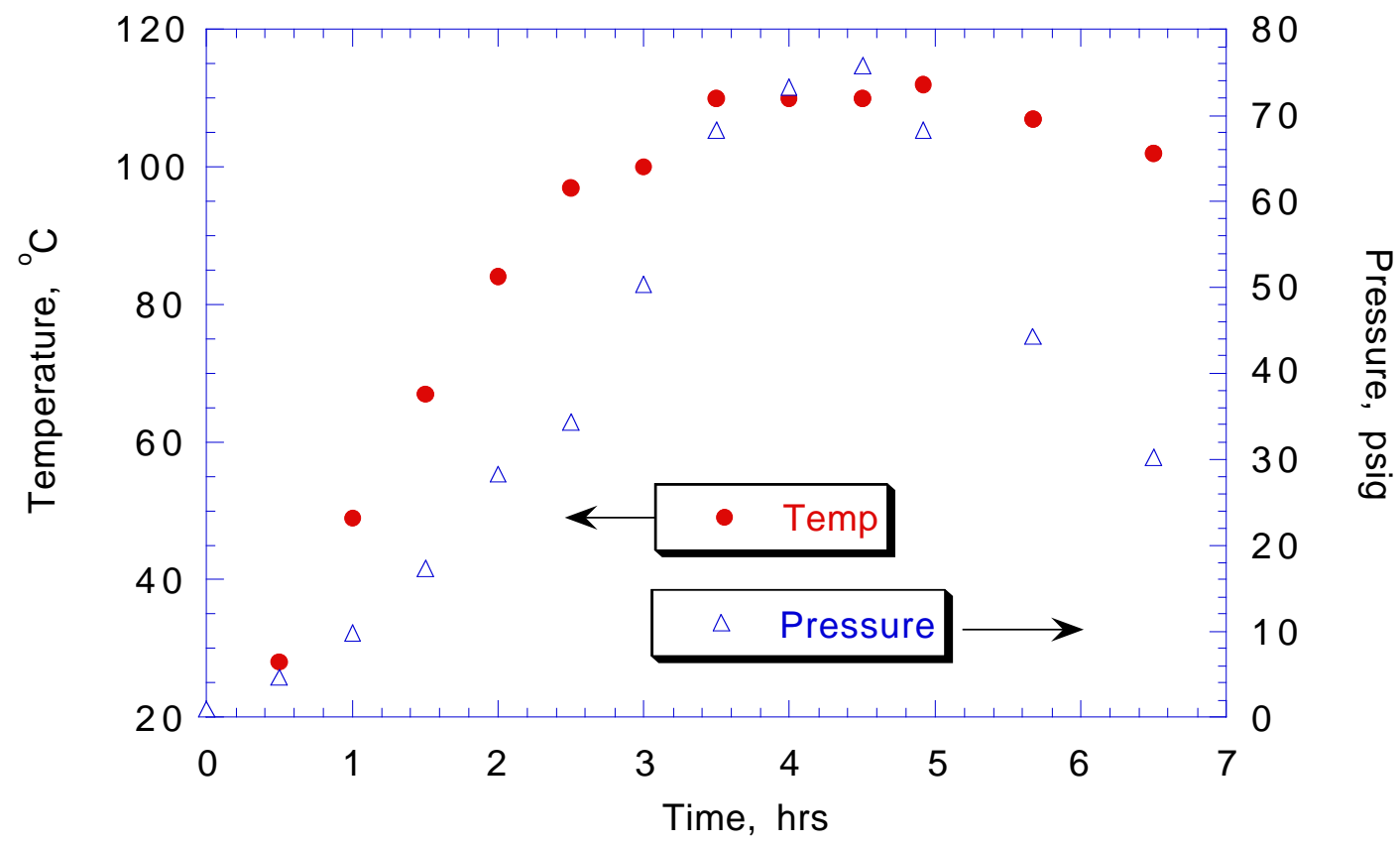

With this integrated system, several different chlorosolvents or chlorosolvent mixtures were tested as shown in Table XI. In the earlier runs \#4 and \#5, the hydrolysis was done using multiple batches of the smaller, laboratory scale mixer, which were then combined for the oxidation runs. The Destruction and Removal Efficiency (DRE) was measured by measuring the amount of organic or inorganic carbon remaining in the waste discharge from the system. These listed DRE values are the results averaged over a run; instantaneous values were often higher $(>99.9 \%)$. Due to the limitations of the analysis method used, the limit of detection of carbon 
corresponds to a DRE of about $99.9 \%$, and thus some of the instantaneous values may be even higher. Note that oxidation of the hydrolysis output by the trio of CSTR's was not done in all cases (Runs 7, 8 and 9), as this portion of the system had already been proven and additional runs would simple result in excess waste with little new data. However, at the end of Runs \#7, \#8 and \#9, there was no second phase and a Total Carbon analysis indicated that (within method limitations) all of the insoluble chloro-organic was present as soluble organic material in the aqueous media.

For Run \#9, the hydrolysis of 1,1,1-trichloroethane was done in a simulated sludge matrix. The composition of this matrix is shown in Table XII below. The total sludge was $6.0 \mathrm{~kg}$, while the hydrolysis solution was 60 liters with 2 liters of 1,1,1-trichloroethane (3\% loading). No unusual problems were noted with the hydrolysis done in this matrix, and the resultant liquid was a single phase which could be easily separated from the solid sludge matrix, if subsequent oxidation by peroxydisulfate is desired.

Table XII. Simulated Sludge Matrix for Hydrolysis Run \#9 of 1,1,1-trichloroethane (3\% loading)

\begin{tabular}{|c|c|}
\hline Component & Weight \% \\
\hline $\mathrm{SiO}_{2}$ (fine) & 60 \\
\hline $\mathrm{Na}_{3} \mathrm{PO}_{4}$ & 10 \\
\hline $\mathrm{Mg}(\mathrm{OH})_{2}$ & 5 \\
\hline $\mathrm{MgO}$ & 5 \\
\hline $\mathrm{Al}_{2}(\mathrm{OH})_{3}$ & 5 \\
\hline $\mathrm{Fe}_{2} \mathrm{O}_{3}$ & 5 \\
\hline $\mathrm{CaSO}_{4}$ & 5 \\
\hline $\mathrm{CaO}$ & 5 \\
\hline
\end{tabular}

Following the hydrolysis of the organic substrate(s), the data from oxidation runs correspond well with the theoretical process model predictions which are based on kinetic constants. A more detailed set of data for a run with 1,1,1-trichloroethane is shown in Table XIII. In each of the three CSTR's, the average DRE matches the predicted value almost exactly. It appears that the relationship is slightly better than expected for the first CSTR, while being slightly less than expected for the third. This is no doubt due to the decreasing oxidant concentration in the third reactor, and a simple remedy would be to add an oxidant makeup system to this final stage as a final polishing step.

Table XIII. Integrated System: Theory vs. Actual DRE's for destruction of 1,1,1-trichloroethane

\begin{tabular}{|c|c|c|c|}
\hline Time, hrs & DRE, CSTR\#1 & DRE, CSTR\#2 & DRE, CSTR\#3 \\
\hline 0.00 & $94.64 \%$ & $99.18 \%$ & - \\
\hline 0.58 & $96.82 \%$ & $99.77 \%$ & $99.81 \%$ \\
\hline 1.17 & $95.36 \%$ & $99.58 \%$ & $99.86 \%$ \\
\hline 2.00 & $92.73 \%$ & $99.32 \%$ & $99.65 \%$ \\
\hline 2.33 & $92.73 \%$ & - & $99.70 \%$ \\
\hline & & & $99.76 \%$ \\
\hline average & $94.45 \%$ & $99.46 \%$ & $99.97 \%$ \\
\hline theory & $93.63 \%$ & $99.59 \%$ & \\
\hline
\end{tabular}


DCO Final Report FY97 43 


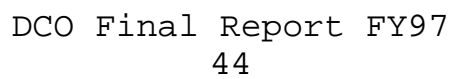

B. Cost Account Status

All work completed and all accounts closed. See budget section below (Section VIII).

$\underline{\text { Milestones Title }}$

C2. Pilot Demo of two DOE problem wastes using DCO

\author{
Completion Date
}

October 1997

Collaborators and Principal Performers

PI: John F. Cooper, Lawrence Livermore National Laboratory co-PI: G. Bryan Balazs, Lawrence Livermore National Laboratory Consultant: Gary Peyton, Illinois State Water Survey, Champaign IL Prospective Advisor: Robert Huie, NIST, Gathersberg 


\section{SUBTASK III.}

\section{A. Summary of Subtask III Progress in FY97}

The EM-50 involvement in the Quickwin '97 Project was to define the process chemistry and engineering scale up data for the destruction of a mixture of heavily chlorinated solvents; this FY97 work has ended. This data is to be used in a treatability study for the destruction of $300 \mathrm{~kg}$ of low-level mixed wastes containing a variety of heavily chlorinated materials. The actual production runs for this treatability study are to be done in collaboration with John Bowers, our EM-30 partner at LLNL. This latter work has not been completed, but is continuing under EM-30 support and it is anticipated that the treatability study will be completed in the first few months of FY98.

\section{B. Specific Accomplishments for FY97}

Because of Quickwin '97 work involved the destruction of heavily chlorinated wastes, both in terms of process chemistry and engineering scale up work, the data for this part has already been covered in Sections IV and V above (Subtasks $1 \& 2$ ). These data, as well as conceptual design and engineering support have been transferred to our EM-30 partners. Initially, a conceptual reactor system was designed and engineered (See Figure 10).

Figure 10. Initial system schematic for Quickwin ‘97

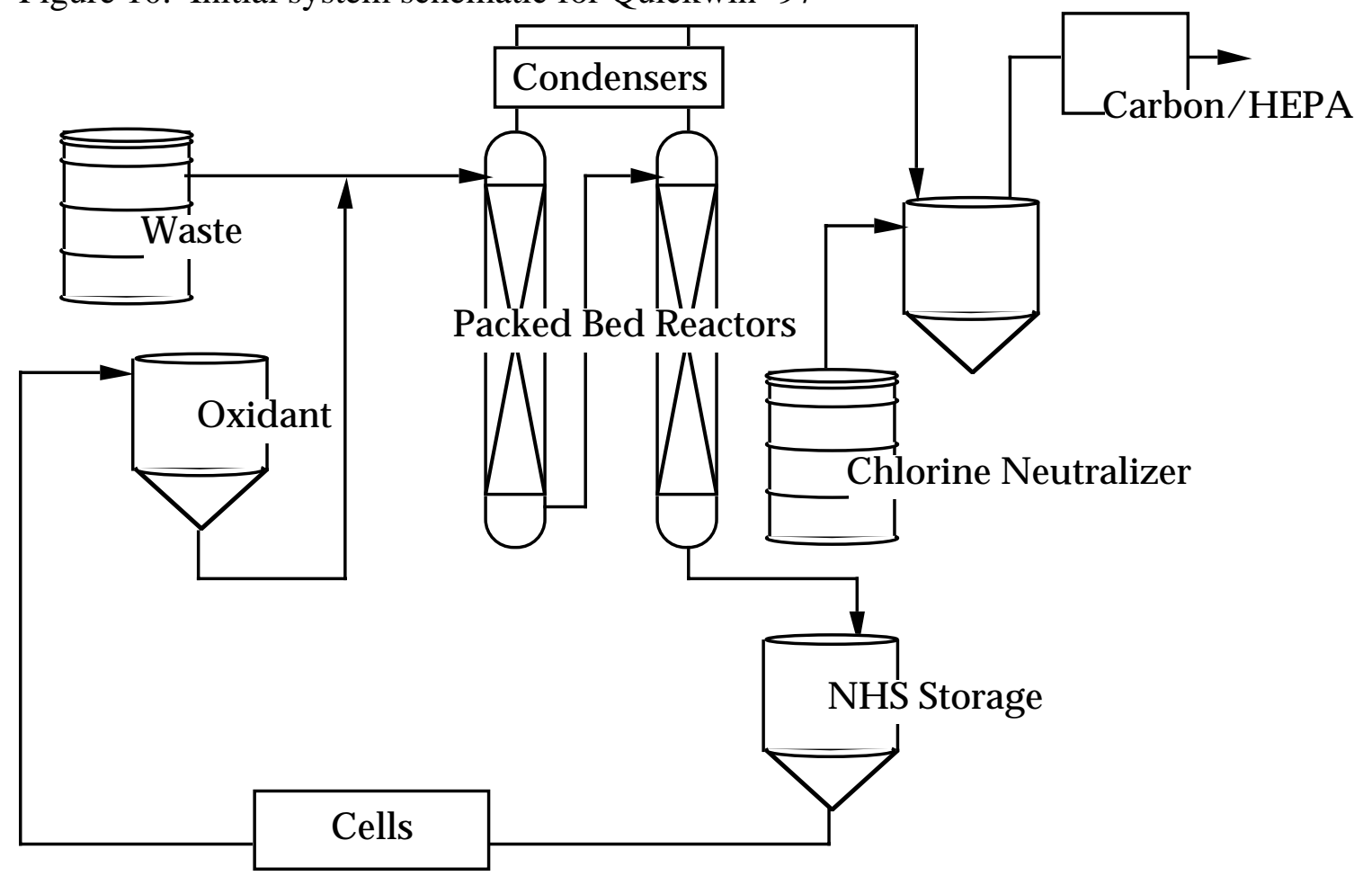

Unfortunately, this design proved to be unworkable for the following reason. It was initially believed that the target waste to be done under this treatability study consisted primarily of perchloroethylene, with minor amounts of 1,1,1-trichloroethane. However, it was later determined that the target waste was primarily 1,1,1-trichloroethane (>90 vol\%). This presented volatility and destruction efficiency issues as mentioned in part 2 of the Subtask I (Section IV above) work 
described above, and the mock up vertical reactor constructed in Subtask I was shown to be insufficient. A new reactor system had to be designed which included a hydrolysis step to convert the chlorosolvents to less volatile and more soluble products. This reactor system was modeled after the Integrated System described in the Subtask II (Section V) description above, and was finished in mid-summer 1997. These reactors have been designed, built, and assembled, albeit behind schedule. Several last minute changes were done strictly for ES\&H issues, as it was believed that work should be temporarily halted until safety issues were resolved. Design of all ancillary systems, such as control, monitoring, and safety, has been completed. Procurement of all components is done, and assembly of the complete system is now nearing completion. It is expected that limited production runs will begin in mid-October.

\section{B. Cost Account Status}

Work Element Letter and Title (FY97):

Subtask 3. Quick Win Project: destruction of chlorinated solvents. Reference QW \#OPE-MWFA96-090

Performance Goals/Deliverables

Pilot demonstration under Quick Win auspices. We will destroy $300 \mathrm{~kg}$ of chlorinated solvent, LL mixed wastes, using potassium or sodium peroxydisulfate, and show recyclability of the sulfate product. Deliverable: reactor hardware and performance documentation.

Pilot demonstrations $(\$ 194 \mathrm{~K}+\$ 89 \mathrm{~K}$ inkind EM-30 support; Jan 1997-Sept. 1997) This project will design, construct and operate a packed bed reactor to destroy $300 \mathrm{~kg}$ of low-level mixed waste solvents, with neutralization of the chlorine offgas using sodium thiosulfate and with a demonstration of recycle of the sulfate product using electrolysis. The project begins with rate measurements on samples of surrogates for methyl chloroform (primary constituent), and develops a scaleup design based on the kinetic data from this work. The pilot plant will be constructed and operated through our EM-30-supported partners headed by John Bowers (Mixed waste manager).

\section{Milestones (Decision Points/Major Accomplishments)}

Milestone Title

C3. Pilot Demo complete of chlorosolvents using peroxydisulfate
Completion Date

September 1997

\section{Cost/Duration of Work Element}

The MWFA cost of this project is $\$ 194 \mathrm{~K}$, including manpower, chemicals and special equipment, purposes the "Pilot demonstration." These funds are supplemented with $\$ 89,450$ of in-kind support from EM-30 (Waste Management Group).

\section{Collaborators and Principal Performers}

PI: John F. Cooper, Lawrence Livermore National Laboratory

co-PI: G. Bryan Balazs, Lawrence Livermore National Laboratory

Engineering Support: Peter Hsu, Lawrence Livermore National Laboratory 
DCO Final Report FY97

47

Consultant: Gary Peyton, Illinois State Water Survey, Champaign IL

EM-30 Contact and partner: John Bowers (LLNL) 
VII. FY98 WORK

DCO Final Report FY97

48

Work Element Letter and Title (FY98):

Investigation of catalysts for DCO and Technology Transfer

Performance Goals/Deliverables

Lab scale experiments on the performance of various transition metal catalyst for the operation of the DCO process at near ambient temperature. Transfer of the DCO technology (FY96-FY98) to a commercial partner. Deliverable: Catalyst performance documentation.

Technical Description of Work (\$100K; Oct. 1997-January 1998) Certain transition metal ions are known to accelerate the oxidation of organics by the peroxydisulfate ion by catalyzing its decomposition into one or two sulfate radical anions. Using diverse organic compounds as surrogate wastes, we will measure the integral rates of oxidation with and without catalysis. Six generic wastes will be examined on the $2 \mathrm{~L}$ reaction vessel level. For each waste, rates will be measured at $90{ }^{\circ} \mathrm{C}$ without catalysis and with 10,30 and $100 \mathrm{ppm}$ levels of catalysts. This task can be substituted for another experimental plan at the discretion of MWFA management. Results will be reported as an appendix to the FY1997 project. In addition, we will speed the transfer of this technology through our currently anticipated industrial partner. This work will involve a proprietary approach to the treatment of undifferentiated wastes in an inert matrix such as soils, gravel, sand or clay.

Milestones Title

Documentation of DCO catalyst performance Addendum to FY97 Final Report
Completion Date

December 1997

February 1998

Cost/Duration of Work Element

The cost of this project is $\$ 100 \mathrm{~K}$, including manpower, chemicals and any equipment.

Collaborators and Principal Performers

PI: G. Bryan Balazs, Lawrence Livermore National Laboratory

co-PI: John F. Cooper, Lawrence Livermore National Laboratory

Engineering Support: Peter Hsu, Lawrence Livermore National Laboratory

Consultant: Gary Peyton, Illinois State Water Survey, Champaign IL 


\section{BUDGET}

\section{A. OVERALL SPENDING PLAN (FY97)}

The overall program spending profile for FY1997 is given in Table XIV below and reflects the varying level of activity related to the completion of the milestones we had proposed for the project.

Table XIV. FY 1997 Actual Spending

\begin{tabular}{|c|c|c|}
\hline Month & Spending, \$K & Quickwin Spending, \$K \\
\hline October & 50.5 & - \\
\hline November & 45.9 & - \\
\hline December & 64.0 & - \\
\hline January & 51.6 & 0.5 \\
\hline February & 49.8 & 27.0 \\
\hline March & 34.0 & 27.2 \\
\hline April & 36.5 & 29.4 \\
\hline May & 26.4 & 43.6 \\
\hline June & 64.0 & 35.6 \\
\hline July & 34.0 & 22.6 \\
\hline August & -11.2 & 11.8 \\
\hline September & 1.2 & 0.5 \\
\hline Total & $\mathbf{4 4 6 . 6}$ & $\mathbf{1 9 4 . 0}$ \\
\hline
\end{tabular}

\section{B. OVERALL SPENDING PLAN (FY98)}

The overall program spending plan for FY1998 is given in Table XV below and reflects the varying level of activity related to the completion of the milestones we have proposed for the project.

Table XV. FY 1998 Projected Spending

\begin{tabular}{|c|c|}
\hline Month & Spending, \$K \\
\hline October & 30 \\
\hline November & 30 \\
\hline December & 30 \\
\hline January & 10 \\
\hline February & 0 \\
\hline March & 0 \\
\hline April & 0 \\
\hline May & 0 \\
\hline June & 0 \\
\hline July & 0 \\
\hline August & 0 \\
\hline September & 0 \\
\hline Total & $\mathbf{1 0 0}$ \\
\hline
\end{tabular}


DCO Final Report FY97 50 
DCO Final Report FY97

\title{
C. BUDGET EXPENSE SCHEDULE
}

FY1996:

Chemical Oxidation

Total FY1996 costs

\$492K

FY1997:

Project Management

Chemical Oxidation

(Quick Win chemical oxidation of chlorosolvents)

Total FY1997 costs

\author{
$\$ 10 \mathrm{~K}$ \\ $\$ 482 \mathrm{~K}$ \\ \$194K \\ $\$ 686 K$
}

FY1998:

Project Management

Chemical Oxidation

Total FY1998 costs

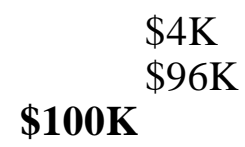




\title{
DCO Final Report FY97 \\ 1 \\ Appendix A. \\ Questions Concerning Safety of Aqueous Peroxydisulfate Oxidizers
}

\author{
John F. Cooper and Bryan Balazs \\ Lawrence Livermore National Laboratory Livermore CA 94550
}

\section{Introduction}

LLNL is currently conducting R\&D into an aqueous ambient pressure, low temperature process for general use in treatment of organic wastes, called "Direct Chemical Oxidation" or "DCO". The process uses dilute aqueous solutions $(0.02-0.04$ mol fraction) of the disodium salt of peroxydisulfuric acid in acidic media to mineralize the organic constituents at temperatures up to $95^{\circ} \mathrm{C}$. The diammonium salt can also be used, but is not preferred because of final waste form issues unrelated to safety. The process is being considered for treatment of organic liquids and solids, paper and rags, chlorinated hydrocarbons, and generic organic components in sludge and soils.

Last year, we discussed the safety concerns raised by an INEL engineer after his reading of the following quotation from Sax's Dangerous Properties of Industrial Materials (8th edition) regarding ammonium peroxydisulfate [1]:

"A powerful oxidizer which can react vigorously with reducing agents. Releases oxygen when heated. Mixtures with sodium peroxide are explosives sensitive to friction, heating above $75{ }^{\circ} \mathrm{C}$, or contact with $\mathrm{CO}_{2}$ or water. Mixtures with powdered aluminum and water, or zinc plus ammonia are explosive. Violent reaction with iron or solutions of ammonia plus silver salts. When heated to decomposition $\left(120^{\circ} \mathrm{C}\right)$ it emits toxic fumes of $\mathrm{SO}_{\mathrm{x}}, \mathrm{NH}_{3}$ and $\mathrm{NO}_{\mathrm{x}}$."

At the time of our discussions last year, we explained that the quotation from SAX, taken out of context, has no direct relevance to DCO or to our research. We have been asked to respond again. Also, we have been asked to comment on LLNL's attitudes with regards to safety in general, on appropriate terminology for sodium peroxydisulfate, and on SAX's reference to an "ammonium peroxo disulfate."

\section{LLNL ES\&H Procedures and Commitments to Safety}

LLNL adheres to the highest standards of safety in its research and development activities, as required by law, long-standing DOE policy and good sense. This project has undergone extensive and repeated safety reviews by an independent ES\&H group within our department. These reviews are documented in project work plans (PWP's) which are required to be updated for each new phase of the experimental program. (See SubAppendix A). This generic research is covered in the building Facility Safety Plan (FSP), and the project complies with all pertinent NEPA requirements. This work has undergone engineering and management prestart reviews as well. We are thoroughly familiar with such safety chemical handbooks as Sax/Lewis, Lewis, and Bretherick, and others.

Our personnel and supervisory management associated with this project and the related mediated electrochemical oxidation (MEO) project (1992-1997) are all degree professionals in chemistry and/or chemical engineering. Each has a minimum of 5 years experience in aqueous oxidation chemistry and engineering. (See SubAppendix B). In addition, we have retained an 
internationally-recognized expert in aqueous peroxydisulfate chemistry -- Gary Peyton, Illinois Water Survey. The Quick Win part of our work is being conducted in collaboration with our Waste Treatment Group headed by John Bowers, a degreed professional chemical engineer.

As required by Laboratory policy and good sense, we store the dry oxidant in sealed containers, in approved chemical storage cabinets, and away from any reducing agents or organic materials. We eliminate all sources of metal from the oxidation system, including mild steel, brass and zinc. Finally, we have designed into the various experimental systems direct thermal control (heating as well as cooling), liquid level monitors, and air overflow. The oxidizers are operated in ES\&H approved and monitored hoods.

\section{Terminology}

The term "peroxydisulfate" refers to the anion $\mathrm{S}_{2} \mathrm{O}_{8}{ }^{2-}$ which is the oxidizing component in sodium peroxydisulfate and ammonium peroxydisulfate. "Peroxodisulfate" is also correct, and appears in more recent literature. Both terms are accepted by the IUPAC. Other common but imprecise terms include persulfate, peroxo disulfate, peroxysulfate, etc. The term "peroxydisulfate" is used in the Merck Index and in CRC handbook, and throughout the literature. CAS returns several thousand listings under this key word. We will continue to use, correctly, such terms as peroxydisulfate, ammonium peroxydisulfate, and sodium peroxydisulfate, as LLNL policy and the context require. CAS lists this material formally as "peroxydisulfuric acid, diammonium salt." We will continue to use, correctly, the term "peroxydisulfate" when we are referring to the oxidizing anion group per se.

\section{Reactivity of pure oxidants and of dilute solutions of oxidants}

The quoted lines from SAX, taken out of context, have no relevance to the safety of the DCO process. Some references are to mixtures of solid peroxydisulfate salts with solid reducing agents such as powdered aluminum. Others references (see below) are to systems which are not under consideration for treatment by DCO, because of instability or extreme reactivity with water.

The reactivity of pure, solid peroxydisulfate salts with reducing agents is vastly different from the reactivity of the dilute (typically 2-4 mol \%) aqueous solutions used by this process. Sax and other handbooks take great pains to distinguish between its references to the substantially pure substance and its references to water solutions of the substance. Solid peroxydisulfate salts intimately mixed with pure reducing agents may indeed be pyrophoric or even explosive. Since DCO uses already diluted solutions of oxidant, the quotation from SAX is not relevant.

In aqueous solution, the reactivity of peroxydisulfate ion is controlled by the slow decomposition of peroxydisulfate into the sulfate radical anion, $\mathrm{SO}_{4}{ }^{-\bullet}$ :

$$
\mathrm{S}_{2} \mathrm{O}_{8}{ }^{2-} \Rightarrow 2 \mathrm{SO}_{4}{ }^{-\bullet}
$$

This is a first order reaction in peroxydisulfate concentration $\left(\mathrm{k}=0.01-0.02 \mathrm{~min}^{-1}\right.$ at $\left.90{ }^{\circ} \mathrm{C}\right)$, but the rate can be increased by using transition metal catalysts or UV.

The chemical and thermal stability of aqueous peroxydisulfate solutions as used in the DCO process is further enhanced by the thermal inertia of the water reaction medium and by the high latent heat of evaporation of water. Finally, the rate of reaction of dissolved peroxydisulfate with solid reducing agents is further limited by ionic diffusion.

\section{"Ammonium Peroxo Disulfate" a form of Peroxydisulfate?}


SAX's reference [1] to ammonium peroxo disulfate is unclear, as the unstable chemical described is not adequately identified. However, from its description, it is clearly not ammonium peroxydisulfate. No reference is made to this substance in a more recent handbook by the same author [2]. Perhaps, SAX is referring to an unstable hydroperoxidate of ammonium sulfate, which is an addition-type compound resulting from the coprecipitation of ammonium sulfate, water and hydrogen peroxide [4]. If so, this is not merely a different "form" of ammonium peroxydisulfate, but a different substance altogether. We have no plans for developing any process for waste treatment using hydroperoxidates, so this should not be of further concern.

\section{Consideration of Quoted Hazards}

Taking the hazards quoted by SAX one at time:

"A powerful oxidizer which can react vigorously with reducing agents" We are studying peroxydisulfates for application to the destruction of organic wastes precisely because it is a powerful oxidizer. The rate of oxidation and temperature is controlled by use of dilute water solutions and systems of great thermal inertia.

"Mixtures [of peroxydisulfate] with sodium peroxide are explosives sensitive to friction, heating above $75^{\circ} \mathrm{C}$, or contact with $\mathrm{CO}_{2}$ or water." SAX also reports [1], in the entry for sodium peroxide, that it can react explosively with water, i.e., without peroxydisulfate. This is because it forms very concentrated hydrogen peroxide, which is explosive, and the reaction is highly exothermic. Because of its reactivity with water, sodium peroxide is not a candidate for treatment by DCO or by any other aqueous oxidation process. The question of reactivity with peroxydisulfate is superfluous. (If found in waste, sodium peroxide can readily be destroyed by careful addition to water, forming sodium hydroxide and dilute hydrogen peroxide. The resultant solution no longer contains sodium peroxide; it can be subsequently acidified and any organic materials present can be treated by peroxydisulfate. No such wastes are under consideration for the current project.)

"Mixtures [of peroxydisulfate] with powdered aluminum and water... are explosive" In SAX's entry for powdered aluminum [1], it states that mixtures with water are explosive, i.e., without peroxydisulfate). This alone rules out treating powdered aluminum wastes with DCO. Questions for reactivity with peroxydisulfate are superfluous. We would not propose treating powdered aluminum, metallic sodium, powdered zinc, lithium hydride, sodium oxide, etc. for similar reasons.

"Mixtures [of peroxydisulfate] with zinc plus ammonia are explosive" Mixtures of ammonia and zinc may form a tetraaminezinc peroxydisulfate, which exploded upon drying [3]. For this reason alone, we would not propose treatment of ammonia simultaneously with zinc. Since DCO is a process operating in acidic sodium peoxydisulfate media, where ammonia does not exist, this rejection may be superfluous.

"Violent reaction with iron" Since Fe(II) ions catalyze peroxydisulfate decomposition to the sulfate radical anion, this point deserves special attention. Bretherick [3] reports, "Iron exposed to the action of a slightly acid concentrated solution of ammonium peroxodisulfate dissolves violently." On the other hand, dilute solutions of peroxydisulfate are commonly used in plating shops to pickle steel and other metals prior to electroplating; stronger solutions are used as commercial etching agents for steel. We have noted a reaction of a magnetic stirring bar (from 
which the Teflon had been partially removed) in our batch oxidizers at $95{ }^{\circ} \mathrm{C}$ fed with dilute peroxydisulfate, but the reaction was mild and steady. We have proposed treating steel turnings with dilute peroxydisulfate, but more research and testing would be required to determine the proper operating regimes. This is not part of our current program, and a safety note is premature.

"Violent reaction with ammonia plus silver salts" Bretheric reports, "In concentrated solutions, the silver catalyzed oxidation of ammonia to nitrogen may be very violent." (italics ours). Silver(I) is oxidized to silver(II) by peroxydisulfate. The $\mathrm{Ag}$ (II) ion then is a charge transfer agent for ammonia oxidation. Wastes under consideration for DCO do not contain either silver or ammonia or their combination. Ammonium ion $\left(\mathrm{NH}_{4}^{+}\right)$in acidified ammonium peoxydisulfate is stable.

"When heated to decomposition $\left(120^{\circ} \mathrm{C}\right)$ it emits toxic fumes of $\mathrm{SO}_{x}, \mathrm{NH}_{3}$ and $\mathrm{NO}_{x}$ " SAX's reference is to solid ammonium peroxydisulfate. DCO is an ambient pressure process, therefore the solution boils between 100 and $104{ }^{\circ} \mathrm{C}$. In dilute solution, the ammonium peroxydisulfate is stable against toxic gas formation, but will decompose to form only oxygen gas even at $95{ }^{\circ} \mathrm{C}$. The $\mathrm{NH}_{4}{ }^{+}$ion is not readily oxidized by peroxydisulfate in acidic solutions.

\section{Historical Notes on the Use of Peroxydisulfate-based Oxidants}

The historical use of peroxydisulfate is of interest in considering the safety of a waste treatment process based on this oxidant. Sodium peroxydisulfate has been used for decades as a oxidant standard for total carbon analysis, and oxidizes organic material at typically $100{ }^{\circ} \mathrm{C}$ to carbon dioxide. Reagents for total carbon analyzers are typically $0.5 \mathrm{M}$ sodium peroxydisufate. These reagents are stored for months in polyethylene bottles, without significant decomposition. [5] Sodium, potassium and ammonium salts of peroxydisulfate were once manufactured on the scale of hundreds of thousands of tons per year, as an intermediate in the production of hydrogen peroxide. Metal (stainless steel 18-8 plus Mo; Krupp V4A alloy; tantalum; and tar coated aluminum) were typical materials that had contact with the solutions. Heat exchangers were typically stainless steels. The concentrations of the salts were generally higher than those used in this work. Today, about 10,000 tons are manufactured in the US for uses as initiators in polymerization reactions, for etching of metals, and for analytical uses, and for specialized organic oxidation reactions. Approximately 3,000 tons per year are used as a breaker for hydraulic fluids (mixtures of agar or hydroxycellulose and water) used in secondary oil and gas recovery.

\section{Conclusions}

Sodium peroxydisulfate in dilute acidic solutions is being evaluated for potential use in waste treatment; in addition, basic solutions may have limited applications. It is attractive in aqueous processes precisely because it is a powerful, nearly universal oxidant, with potentially widespread applications to organic materials. The ES\&H reviews of our project have been appropriately conducted with the actual testing procedures and waste surrogates in mind. We have designed our system to assure the safety of all personnel and equipment.

The fact that substances can be found (such as powdered aluminum and zinc, sodium peroxide, etc.) that react violently with water with or without peroxydisulfate does not mean that this process is inherently unsafe or that LLNL ES\&H practices are inadequate. We have taken appropriate steps to assure that these materials do not come into contact with the system. If wastes are ever considered which contain these materials, it would behoove the waste treatment manager 


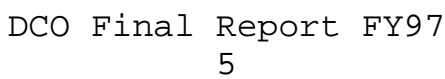

to take appropriate steps to determine operating conditions for this process which mitigate the danger, or to reject treatment of these materials.

\section{References}

1. Richard J. Lewis, SAX's dangerous properties of industrial materials," 9th editions, van Nostrand Reinhold, New York 1995.

2. Richard Lewis, Hazardous Chemicals Desk Reference, 4th edition, Van Nostrand Reinhold, New York 1997.

3. L. Bretherick, Reactive chemical hazards, Butterworths London 1990.

4. Walter Schumb, Charles Satterfield, Ralph Wentworth, Hydrogen Peroxide, Reinhold Publishing Corporation, New York, 1955.

5. Gary Peyton, "The free-radical chemistry of persulfate-based total organic carbon analyzers," Marine Chemistry 41, 91-103 (1993). 
DCO Final Report FY97

6

\section{SubAppendix A.}

Partial Listing of Environmental Health and Safety Reviews of Direct Chemical Oxidation Research and Development

1. Project Work Plan \# 6263-01 "Direct chemical oxidation” May 16, 1996; concurrent ES\&H Review.

2. Project Work Plan \# 7044-01 "Direct chemical oxidation: preliminary work for chlorosolvent treatability study under Quick Win '97 Proposal," Jan 23, 1997. Concurrent ES\&H Review

3. Project Work Plan \# (to be assigned). "Direct chemical oxidation: scaleup work for organic destruction using direct chemical oxidation (DCO)," submitted May 1997 and currently under review.

4. Building 241 Facility Safety Procedure (FSP), Issued April 1996; expires April 1999.

5. Building 235 Facility Safety Procedure (FSP), Issued February 1997; expires August 301997.

\section{SubAppendix B.}

Listing of Qualifications of Supervisory and Technical Participants in the Direct Chemical Oxidation Project and Quick Win, 1996-7. All have advanced degrees in chemistry and/or chemical engineering. All of these individuals are LLNL employees.

\begin{tabular}{|l|l|}
\hline $\begin{array}{l}\text { Dr. Joseph Farmer, Group Leader } \\
\text { Electrochemical Processes }\end{array}$ & $\begin{array}{l}\text { Internationally recognized expert in aqueous } \\
\text { electrochemical waste treatment technologies }\end{array}$ \\
\hline Dr. John F. Cooper, Principal Investigator & $\begin{array}{l}\text { Inventor; 5 years experience in aqueous waste } \\
\text { treatment technologies including MEO and } \\
\text { DCO }\end{array}$ \\
\hline $\begin{array}{l}\text { Dr. Bryan Balazs, Co-Principal Investigator } \\
\text { 5 years experience in mediated electrochemical } \\
\text { oxidation and DCO }\end{array}$ \\
\hline $\begin{array}{l}\text { Dr. Frances Wang, Co-principal investigator } \\
\text { 1996 }\end{array}$ & $\begin{array}{l}5+\text { years experience in aqueous treatment } \\
\text { technologies including MEO, DCO, Fenton's, } \\
\text { UV-catalyzed peroxide, etc. }\end{array}$ \\
\hline $\begin{array}{l}\text { Dr. Peter Hsu, current development of pilot } \\
\text { facilities. }\end{array}$ & $\begin{array}{l}5+\text { years experience in chemical engineering of } \\
\text { MEO and DCO }\end{array}$ \\
\hline $\begin{array}{l}\text { John Bowers, head, Waste Treatment Facility } \\
10 \text { years experience in waste treatment } \\
\text { technologies; degreed professional Chemical } \\
\text { Engineer. }\end{array}$ \\
\hline
\end{tabular}

In addition, this project has retained an internationally-recognized expert in aqueous peroxydisulfate oxidation chemistry, Gary Peyton, Illinois Water Survey, Urbana-Champaign IL. 
Appendix B Integrated System Pictures

\section{Integrated System}

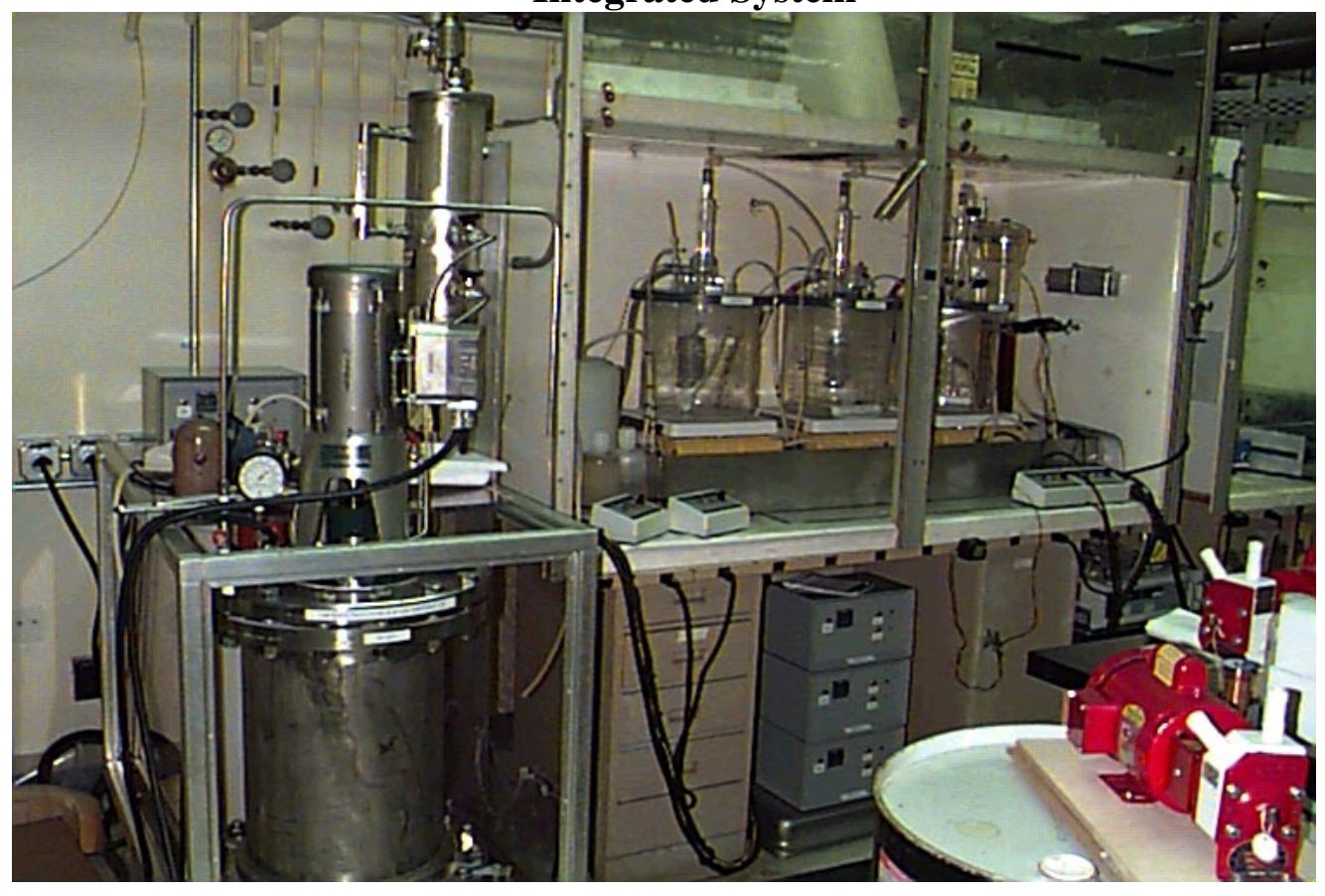


DCO Final Report FY97

8

Hydrolysis Vessel

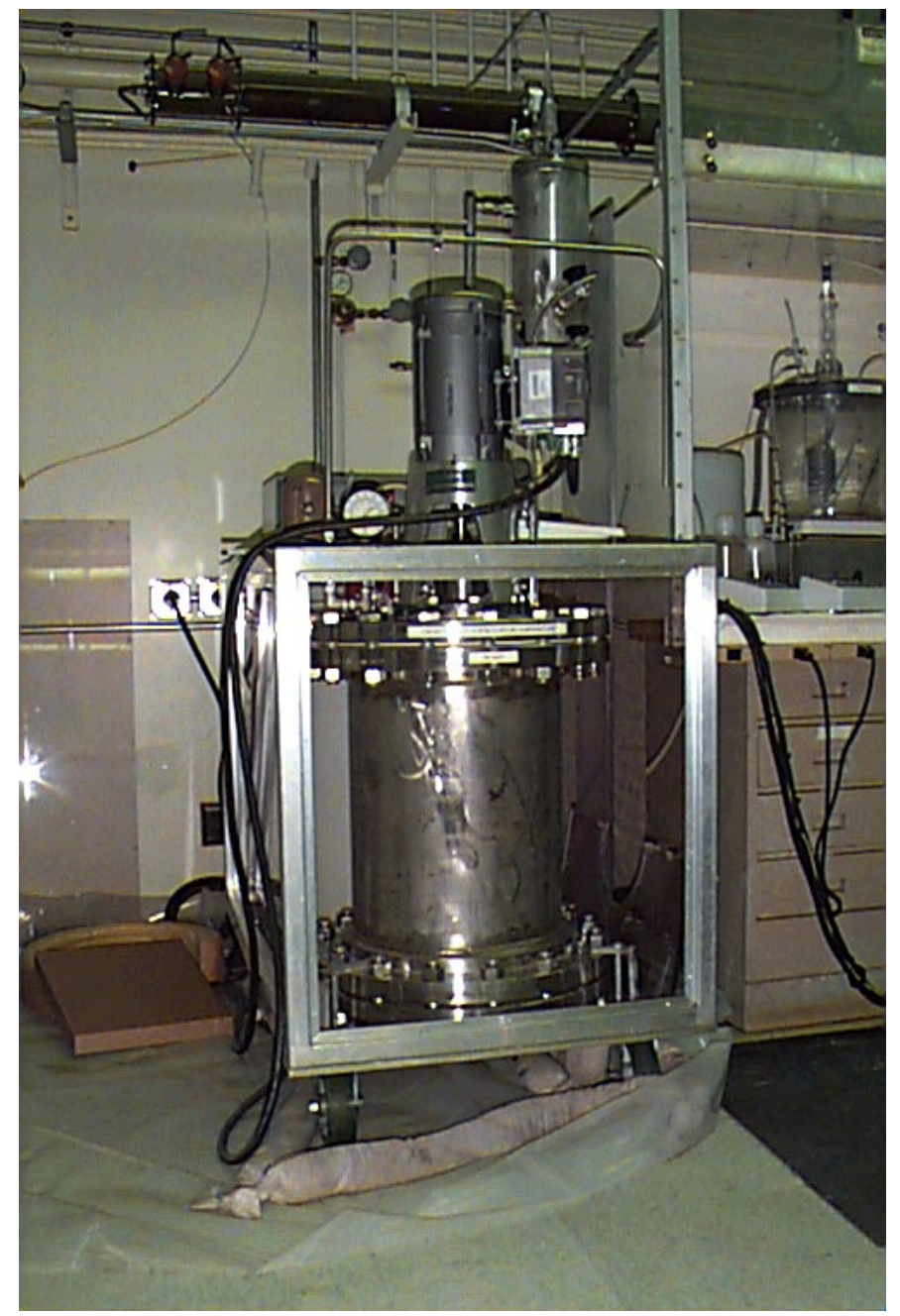


DCO Final Report FY97

Cascaded Continuous Stirred Tank Reactors (CSTR)

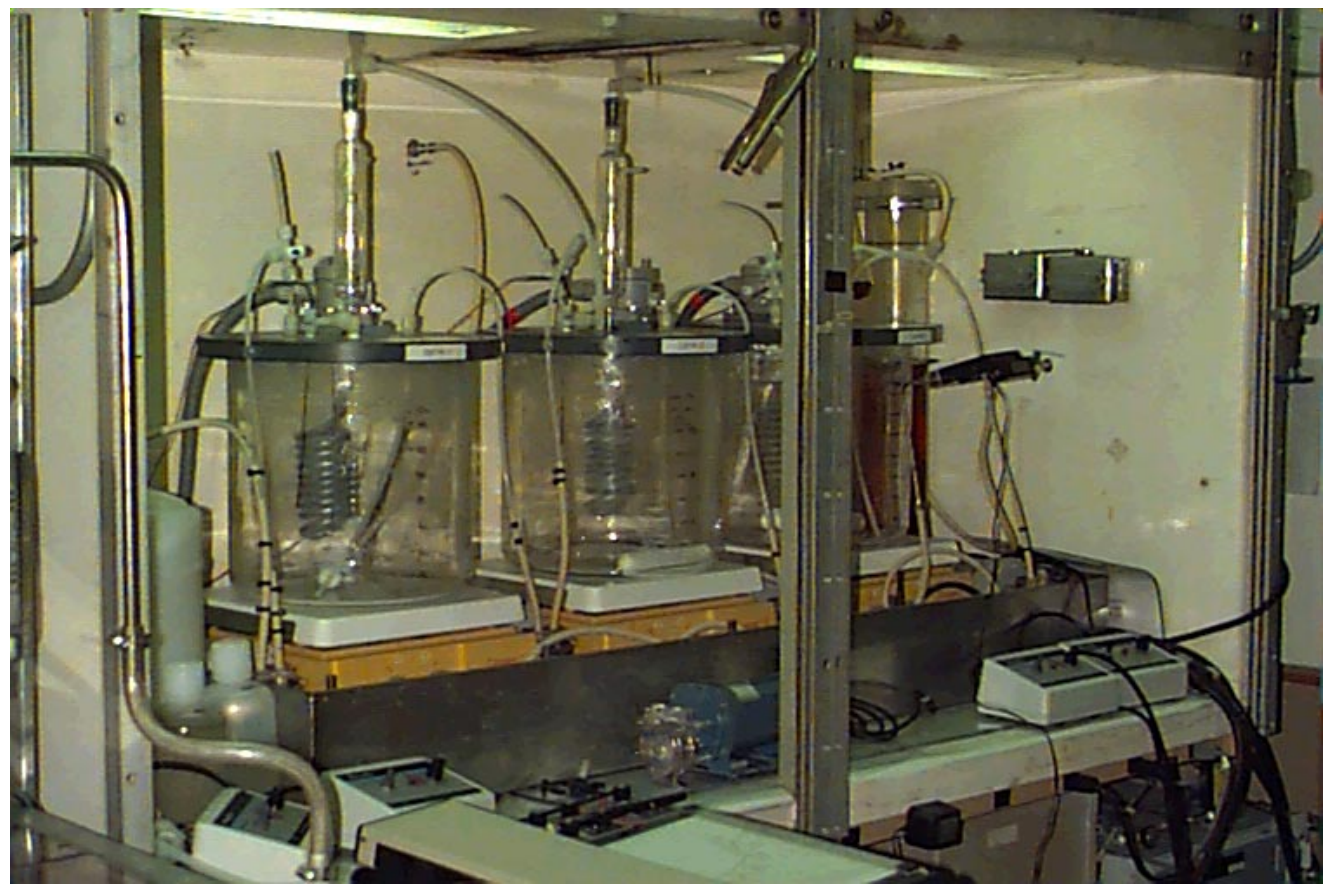




\section{Appendix C. List of Publications in FY97}

(1) J. Cooper, F. Wang, B. Balazs, R. Krueger, P. Lewis, T. Shell, J. Farmer, M. Adamson, "Destruction of organic wastes by ammonium peroxydisulfate," presented at AIChE Spring National Meeting (March 9-13, 1997), Houston, TX, UCRL-MI-126794.

(2) Balazs, G. B. and Cooper, J. F., "The Effect of Trace Additives on the Efficiency of Peroxydisulfate Regeneration," in preparation.

(3) Cooper, J. F., Wang, F., Balazs, G. B., Shell, T., Krueger, R., Lewis, P., Adamson, M., "Omnivorous Waste Destruction Process Using Uncatalyzed Peroxydisulfate Solutions," poster presentation at WM '97 conference, Tuscon, Arizona, March 2-6, 1997, UCRL-MI-126764.

(4) J.F. Cooper, F. Wang, B. Balazs, R. Krueger, P. Lewis, M. Adamson. "Demonstration of Omnivorous Non-Thermal Mixed Waste Treatment: Direct Chemical Oxidation Using Peroxydisulfate," First annual report to Mixed Waste Focus Area, November, 1996.

(5) Patent Disclosure, IL-10221, "Integrated System of Hydrolysis with Oxidation by Peroxydisulfate for the Destruction of Chlorinated Solvents," John F. Cooper, G. Bryan Balazs, Peter C. Hsu, Martyn Adamson, Patricia R. Lewis. 


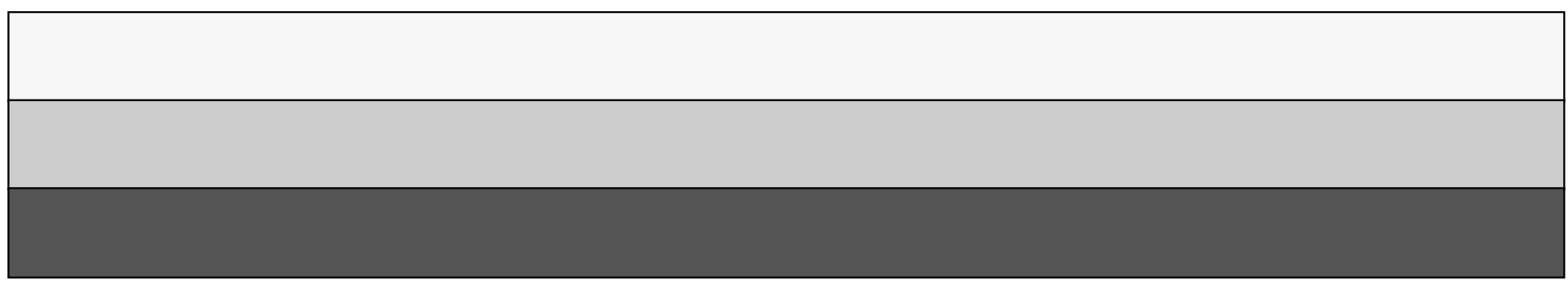

